\title{
EFFECTS OF INHIBITORS ON SYNTHESIS OF ESTERIFIED ALKAN-2-OLS IN BARLEY SPIKE EPICUTICULAR WAX
}

\author{
by \\ PENNY von WETTSTEIN-KNOWLES \\ Institute of Genetics, University of Copenhagen, \\ Øster Farimagsgade 2A, DK-1353 Copenhagen K \\ and \\ Department of Physiology, Carlsberg Laboratory, \\ Gamle Carlsberg Vej 10, DK-2500 Copenhagen Valby
}

\begin{abstract}
Keywords: $\beta$-ketoacyl elongase, palmityl elongase, arsenite, cyanide, $\beta$-diketones, fatty acid synthetase, 3-oxoacyl-CoA, eceriferum mutants, Gramineae
\end{abstract}

\begin{abstract}
Labelled fatty acids were fed to tissue slices prepared from spikes of barley eceriferum mutants directly or after pretreatments with inhibitors. The epicuticular waxes were isolated and the distributions of label determined within and/or among the hydrocarbons, esters, ester moieties (fatty acids, alkan-1-ols, alkan-2-ols) and aldehydes with the aid of radio-thin layer chromatography and -gas chromatography. Arsenite, a known inhibitor of $\beta$-diketone synthesis, blocked esterified alkan-2-ol synthesis, suggesting that it acts on the $\beta$-ketoacyl elongase involved in formation of both these wax lipids. In this respect $\beta$-ketoacyl elongase is similar to palmityl elongase and differs from fatty acid synthetase. By contrast, cyanide known to prohibit $\beta$-diketone synthesis from $C_{18}$ 3-oxoacyl-CoA had little effect on esterified alkan-2-ol synthesis from $\mathrm{C}_{14}$ and $\mathrm{C}_{16}$ 3-oxoacyl-CoAs. Arsenite, cyanide and mercaptoethanol impeded elongation of the short acyl chains serving as precursors of the ester acids. The tissue slices synthesized in addition to the expected alkan-1-ol and alkan-2-ol esters a third type having the same acid moieties esterified to unknown alcohols which if primary must have 2-10 carbons.
\end{abstract}

\section{INTRODUCTION}

Elongases are enzyme complexes that add $\mathrm{C}_{2}$-units to an intermediate or product of fatty acid synthetase (fas) or another elongase. Several of these complexes are involved in biosynthesis of barley epicuticular lipids. A major branch point in these pathways occurs with the formation of acyl-CoAs vs 3-oxoacyl-CoAs $(22,24)$. One or more acyl elongases utilize the former in constructing the carbon chains of hydrocarbons, alkan-1-ol esters, aldehydes, primary alcohols and free acids. By contrast, the $\beta$-ketoacyl elongase in vivo participates in $\beta$-diketone and hy- droxy- $\beta$-diketone synthesis almost exclusively via a $\mathrm{C}_{18}$ 3-oxoacyl-CoA and in alkan-2-ol and 7-oxoalkan-2-ol ester formation preferentially via $\mathrm{C}_{14}$ and $\mathrm{C}_{16}$ 3-oxoacyl-CoAs $(22,31,33)$.

In the course of demonstrating the existence of different elongation systems for hydrocarbons and $\beta$-diketones, the effect of inhibitors on the subsequent incorporation of labelled acetate into the wax lipids of $c e r-u^{69}$ spikes was studied (23). The hydrocarbons compose $16 \%$ and the $\beta$-diketones $50 \%$ of the wax on spikes of this mutant which is blocked in insertion of the hydroxyl group into the $\beta$-diketone chain,

Abbreviations: $\mathrm{AS}=$ meta -arsenite $\mathrm{CN}=$ potassium cyanide; fas = fatty acid synthetase $; \mathrm{GC}=$ gas chromatography; $\mathrm{ME}=2$-mercaptoethanol; $\mathrm{TLC}=$ thin layer chromatography; $\mathrm{TMS}=$ trimethylsilyl . 
whereas the alkan-2-ol esters account for only $4.7 \%$ (35). Not surprisingly, therefore, identification of sites of action of two of the tested inhibitors, namely, meta-arsenite (AS) and potassium cyanide $(\mathrm{CN})$, close to the branch point of the acyl and $\beta$-ketoacyl elongase pathways was based upon effects on the $\beta$-diketones and hydrocarbons $(20,23)$. Since, as implied above, the ester alkan-2-ol pathway diverges from that of the $\beta$-diketones already with the formation of 3-oxoacyl-CoAs by the $\beta$-ketoacyl elongase, the effects of AS and CN as well as of 2-mercaptoethanol (ME) on ester alkan-2-ol synthesis have been investigated. Spike tissue slices from cer$c^{36}$, another allele of the same gene as $c e r-u^{69}$, have been used as the major wax lipids in this mutant are the alkan-2-ol esters; neither $\beta$-diketones nor hydroxy- $\beta$-diketones occur $(28,31$, 36). The results reveal that AS inhibits the $\beta$-ketoacyl elongase, as it does the $\mathrm{C}_{16}$ elongase $(10,11,13,14,16,26)$, while $\mathrm{CN}$ selectively impedes use of $\mathrm{C}_{18}$ 3-oxoacyl-CoA but has little effect on use of $\mathrm{C}_{14}$ and $\mathrm{C}_{16}$ 3-oxoacyl-CoAs. In addition, all three substances inhibit elongation of short acyl chains destined for the ester acids.

\section{MATERIALS AND METHODS}

\subsection{Materials}

Seeds of the barley (Hordeum vulgare L.) eceriferum mutants cer- $c^{36}$ and $-q^{42}$ (36) were planted and grown in the Phytotron (27) at the Swedish University of Agricultural Science, Stockholm between 1976 to 1979 under optimum conditions for vegetative growth $(6,7)$ except that the nitrogen in the Hoagland solution used for twice daily watering was increased to $100 \mathrm{mg}$ per liter.

Stock solutions of CN and AS from Merck, Darmstadt, West Germany and ME from Serva, Heidelberg, West Germany were prepared and the $\mathrm{pH}$ adjusted to 6.2-6.3 using $\mathrm{NaOH}$ or $\mathrm{HCl}$. Dilution series of the inhibitors were prepared using the available deionized water at $\mathrm{pH} 6.2$ 6.3. Sodium $\left(1-{ }^{14} \mathrm{C}\right)$-acetate was dissolved in water while $\left(1-{ }^{14} \mathrm{C}\right)$-lauric, -myristic, -palmitic and -stearic acids as well as $\left(2-{ }^{14} \mathrm{C}\right)$ - and $\left(9,10^{3} \mathrm{H}\right)$ palmitic acids were dispersed using Tween-20 $\left(1 \mathrm{mg} \cdot \mathrm{ml}^{-1}\right)$ and sonication (23). All isotopes were from the Radiochemical Centre (Amers- ham, England), except for one batch of $\left(1-{ }^{14} \mathrm{C}\right)-$ $\mathrm{C}_{14}$ and the $\left(2-{ }^{14} \mathrm{C}\right)-\mathrm{C}_{16}$ acids that were purchased from Applied Science Laboratories, State College, PA, USA. The latter and Analabs, North Haven, CT, USA were the suppliers of the esters, methyl esters and alcohols used as standards and/or carriers. The $\mathrm{K}_{2} \mathrm{Cr}_{2} \mathrm{O}_{7}$ used was from Merck, the $10 \% \mathrm{BF}_{3}$ in $\mathrm{CH}_{3} \mathrm{OH}$ was from Supelco Inc., Bellefonte, PA, USA, and the analytical grade chloroform from Riedel-deHaen, Hannover, West Germany unless specified otherwise.

\subsection{Incorporation experiments and isolation of wax classes}

Intact spikes, of which $5-10 \mathrm{~cm}$ remained enclosed in the leaf sheaths, were harvested from heading plants in the $10^{\circ} \mathrm{C}$ phase of the temperature cycle. They were either used directly or 2-3 $\mathrm{mm}$ tissue slices were prepared therefrom (23). All incubations took place in a $20^{\circ} \mathrm{C}$ room of the Phytotron in $100 \mathrm{ml}$ glass stoppered Erlenmeyer flasks that were placed on a gently shaking table. For experiments intended to compare substrates and/or effects of inhibitors on ester synthesis, tissue slices from two spikes minus awns (1.1-1.3 g) were used per treatment. After 0.5 hours in 5 ml of water or the appropriate inhibitor solution, labelled substrate was added and the volume increased to $10 \mathrm{ml}$ with water. By comparison, to provide large amounts of labelled esters to assist in their identification, tissue slices were pooled from sufficient spikes and 1.0 or $1.1 \mathrm{~g}$ aliquots transferred to each flask containing the labelled substrate in a total volume of $10 \mathrm{ml}$. Three or six hours after the labelled substrate was added, syntheses were stopped by the addition of $0.5 \mathrm{ml}$ $5 \mathrm{~N}_{-} \mathrm{H}_{2} \mathrm{SO}_{4}$ (23). The epicuticular waxes were extracted and the non-metabolized acid substrates recovered by adding $30 \mathrm{ml}$ of chloroform and shaking vigorously for $30 \mathrm{sec}$ (18). The lower chloroform phase was sucked out, passed through a paper filter, dried with anhydrous $\mathrm{Na}_{2} \mathrm{SO}_{4}$ and then taken to dryness under nitrogen.

The soluble substances were taken up in warm petroleum ether (b.p. $40-60^{\circ} \mathrm{C}$ ) and transferred to a $4-5 \mathrm{~cm} \mathrm{NaOH}$ column (30) that had been prewashed with petroleum ether. After $200 \mathrm{ml}$ of petroleum ether was passed through the column 
at room temperature, it was dried under nitrogen yielding the epicuticular waxes minus the free acids and most of the non-metabolized substrates and complex lipids. The samples were dissolved in small volumes of chloroform for preparative thin layer chromatography (TLC) on $5 \times 20 \mathrm{~cm}$ silica gel $\mathrm{H}$ type 60 (Merck) plates. When acetate had served as the labelled substrate, $2-5 \times 10^{4} \mathrm{cpm}$ were applied per plate, whereas when the longer acids were used 1.6$2 \times 10^{5} \mathrm{cpm}$ were applied. After being developed first with hexane and then with benzene, the plates were radio-scanned. One plate from each treatment was used for quantitation of all radioactive bands (23), while from the others hydrocarbon, esters and aldehydes were recovered by eluting with chloroform (36). Rechromatography of the esters was carried out until a single radioactive band was present when $2 \times 10^{4} \mathrm{cpm}$ were subjected to radio-TLC. Furthermore, to ensure that aldehydes were not present in the esters isolated from the pooled experiments or in those studied in Table VIII, they were subjected to treatment with $\mathrm{NaBH}_{4}(20)$.

\subsection{Chemical reactions}

To aliquots of dried esters, approx. $1 \mathrm{mg}$ each of $\mathrm{C}_{14}$ alkan-1-ols plus $\mathrm{C}_{13}$ and $\mathrm{C}_{15}$ alkan-2-ols were added, and the solvent removed using nitrogen before carrying out transesterification (20). The resulting mixture of acids as methyl esters plus the ester derived alcohols and carrier alcohols were exposed to $\mathrm{K}_{2} \mathrm{Cr}_{2} \mathrm{O}_{7}$ to oxidize the alkan-2-ols into methyl ketones and the alkan-1ols into free acids $(22,32)$. The three lipid classes were separated on $5 \times 20 \mathrm{~cm}$ silica gel $\mathrm{H}$ plates by developing with benzene ( $R \mathrm{fs}$ : methyl esters = 0.43 , methyl ketones $=0.22$ and free acids $=$ 0.02) or amylene stabilized chloroform (Merck). Approx. $5 \times 10^{5} \mathrm{cpm}$ were applied to each plate. After radio-scanning one plate from each sample was used for quantitation of radioactivity (23) while the methyl esters and methyl ketones were recovered from the additional plates using chloroform.

Aliquots of $\left(1-{ }^{14} \mathrm{C}\right)-\mathrm{C}_{12}$ labelled esters from cer-c $c^{36}$ and $-u^{69}$ tissue slices were subjected to base hydrolysis (28). The resulting nonconcentrated hexane extracts containing the alcohol and acid moieties were then added to a Sep-pak Silica Cartridge (3). The alcohols were eluted using several small aliquots of benzene totalling $10 \mathrm{ml}$, whereafter the acids were recovered by eluting with $10 \mathrm{ml}$ of chloroform:methanol (1:1, v/v). $C_{13}+C_{15}$ alkan-2-ols were added to the former and $\mathrm{C}_{16}-\mathrm{C}_{26}$ methyl esters to the latter, before trimethylsilyl (TMS) derivatives of the alcohols and methyl esters of the acids were prepared as described in references 21 and 28 , respectively.

\subsection{Radio-gas chromatography (radio-GC)}

Esters isolated from spikes of $c e r-c^{36}(36)$ were injected simultaneously with $1.5-2 \times 10^{4} \mathrm{cpm}$ aliquots of the herein studied esters into a radio-gas chromatograph (21). Total flow entering the proportional counter was $30 \mathrm{ml} \cdot \mathrm{min}^{-1}$. Either a 152 or $183 \mathrm{~cm} \times 2 \mathrm{~mm}$ (i.d.) stainless steel column packed with $1 \%$ Dexsil-300 on 100/120 mesh Supelcoport (Supelco) was programmed at $1{ }^{\circ} \mathrm{C} \cdot \min ^{-1}$ from $200-345^{\circ} \mathrm{C}$, and the ${ }^{14} \mathrm{C}$ distribution determined as described (21). The following modifications were made for analyses of ester moieties isolated from $c e r-c^{36}$ and $-u^{69}$ tissue slices fed $\left(1-{ }^{14} \mathrm{C}\right)-\mathrm{C}_{12}$ acid. Methyl esters of even numbered 16-26 carbon acids were coinjected with $1-1.5 \times 10^{4} \mathrm{cpm}$ aliquots of the ester acid methyl esters. By comparison only $\mathrm{C}_{13}$ and $\mathrm{C}_{15}$ alkan-2-ols served as carriers for the $0.8-1 \times 10^{4} \mathrm{cpm}$ aliquots of total ester alcohols as their TMS derivatives. Quantities of the alkan-1ol TMS derivatives were sufficiently large for the $c e r-u^{69}$, but not for the $c e r-c^{36}$, sample so that the accompanying radioactive peaks were sharp and symmetrical (2). Temperature programming for the acid moieties started at $120^{\circ} \mathrm{C}$ and for the alcohol moieties at $100^{\circ} \mathrm{C}$.

Collection of individual or groups of esters by preparative radio-GC was accomplished as previously detailed (34). The instrument described in reference 22 was used with either the $10 \%$ SE-30 or the 3\% SP-2100 column. After injection at either 150 or $200^{\circ} \mathrm{C}$ the temperature was increased at $3{ }^{\circ} \mathrm{C} \cdot \mathrm{min}^{-1}$ until the desired esters were collected, whereupon the temperature was increased to $340{ }^{\circ} \mathrm{C}$ to remove as rapidly as possible the remaining sample from the column. Samples were coinjected with a mixture of $\mathrm{C}_{26}, 28$, 
P. VON WETTSTEIN-KNOWLEs: Synthesis of esterified alkan-2-ols

Table I.

Incorporation of $\left(1-{ }^{14} \mathrm{C}\right)$-labelled precursors during six hours into three lipid classes by $c e r-c^{36}$ spikes and tissues thereof $\left(\mathrm{cpm} \times 10^{-4}\right)^{n}$.

\begin{tabular}{|c|c|c|c|c|c|}
\hline \multirow[b]{2}{*}{ Tissue $^{b}$} & \multirow[b]{2}{*}{ Precursor $^{c}$} & & \multicolumn{3}{|c|}{ Wax class } \\
\hline & & & Aldehyde & Ester & Hydrocarbon \\
\hline Whole spikes & Acetate & $\left(\mathrm{C}_{2}\right)$ & 2.6 & 1.8 & 3.5 \\
\hline \multicolumn{6}{|l|}{ Tissue slices } \\
\hline Awns & Acetate & & 2.0 & 8.4 & 9.7 \\
\hline Spikes minus & Acetate & & 2.4 & 15.1 & 3.6 \\
\hline \multirow[t]{7}{*}{ awns } & Laurate & $\left(C_{12}\right)$ & 3.6 & 33.8 & 2.7 \\
\hline & Myristate & $\left(\mathrm{C}_{14}\right)$ & 8.6 & 28.4 & 1.9 \\
\hline & & & 7.7 & 35.4 & 2.1 \\
\hline & & & 12.5 & 46.8 & 2.8 \\
\hline & & & 26.0 & 52.1 & 1.6 \\
\hline & Palmitate & $\left(\mathrm{C}_{16}\right)$ & 65.9 & 85.6 & 8.7 \\
\hline & Stearate & $\left(C_{18}\right)$ & 127.4 & 71.6 & 5.1 \\
\hline \multicolumn{6}{|c|}{$\begin{array}{l}\text { The epicuticular lipids were separated by TLC, located via radio-scanning and quantitated via scintillatic } \\
\text { counting as detailed in section } 2.2 \text {. } \\
\text { b In all cases two spikes minus the awns served as the starting material. }\end{array}$} \\
\hline
\end{tabular}

${ }_{32}$ and ${ }_{36}$ ester standards. Subsequent to collection an aliquot of approx. $2 \times 10^{4} \mathrm{cpm}$ of each ester or group thereof was reinjected and chromatographed under appropriate conditions to ascertain radioactive purity. The same instrument and conditions were used for the experiment in Table VIII.

For quantitation of the radioactive distributions of the acid methyl esters and methyl ketones recovered from radio-thin layer chromatographic plates, the just mentioned instrument containing the $10 \%$ SE- 30 column (22) was used unless specified. Instrument settings were as described for methyl esters except that the column temperature was programmed from $120-270^{\circ} \mathrm{C}$. With each acid methyl ester aliquot of $0.8-5.7 \times 10^{4} \mathrm{cpm}$ injected, a mixture of methyl esters having 14-24 carbons was coinjected. This was not necessary for the methyl ketones as $C_{13}$ and $\mathrm{C}_{15}$ alkan-2-ols had been added before the transesterification reaction was started. Entire available methyl ketone samples were injected.

\section{RESULTS AND DISCUSSION}

\subsection{Incorporation of labelled precursors into wax lipid fractions by spike tissues}

The data in Table I illustrate the abilities of whole spikes of $c e r-c^{36}$ vs tissue slices prepared from their awns and spikes minus awns to incorporate labelled precursors into three wax classes readily separated by TLC. The distribution of label among these lipids after feeding $\mathrm{C}_{2}$-acid to whole spikes for six hours is similar to that reported for another allele at the same multifunctional locus, $c e r-u^{69}$, when incorporation was for two hours $(20,23)$. Feeding $\mathrm{C}_{2}$-acid to the two tissue slice systems resulted in two different distributions of label. While none of the three distributions resembles the in vivo composition (36), the increased hydrocarbon synthesis by the awn system may result from absence of an active $\beta$-ketoacyl elongase in this tissue (19).

Increasing the chain length of the $\left(1-{ }^{14} \mathrm{C}\right)$-fatty acids fed to tissue slices of $c e r-c^{36}$ spikes minus awns had relatively little effect on hydrocarbon synthesis confirming earlier observations with $\operatorname{cer}-u^{69}(21,23)$, but apparently resulted in a 
Table 11.

Incorporation during six hours of labelled precursors into the ester moieties by tissue slices prepared from $c e r-c^{36}$ spikes minus the awns (cpm $\left.\times 10^{-4}\right)^{*}$.

\begin{tabular}{|c|c|c|c|c|}
\hline \multirow[t]{2}{*}{ Precursor } & \multirow{2}{*}{$\begin{array}{l}\text { Specific activity } \\
\left(\mathrm{mCi} \cdot \mathrm{mmol}^{-1}\right)\end{array}$} & \multicolumn{3}{|c|}{ Ester } \\
\hline & & Acid & Alkan-1-ol & Alkan-2-ol \\
\hline$\left(1-{ }^{14} \mathrm{C}\right)$-acetate & 58.1 & 12.8 & 1.0 & 0.6 \\
\hline -laurate & 31.2 & 20.3 & 2.9 & 6.3 \\
\hline -myristate & 45.0 & 45.8 & 2.2 & 4.1 \\
\hline -palmitate & 57.7 & 83.1 & 2.5 & n.d. \\
\hline$\left(2-{ }^{14} \mathrm{C}\right)$-palmitate & 19.0 & 74.3 & 10.6 & n.d. \\
\hline$\left(9,10^{3}-\mathrm{H}\right)$-palmitate & 500 & 65.2 & 7.8 & 0.5 \\
\hline & & 71.9 & 14.1 & 13.8 \\
\hline$\left(1-{ }^{14} \mathrm{C}\right)$-stearate & 58.0 & 70.2 & 2.2 & n.d. \\
\hline
\end{tabular}

a The esters were isolated and subjected to transesterification followed by $\mathrm{K}_{2} \mathrm{Cr}_{2} \mathrm{O}_{7}$ oxidation. The acid moieties as methyl esters, the alkan-1-ols as free acids and the alkan-2-ols as methyl ketones were separated by TLC and quantitated via scintillation counting as described in section 2.3 . A minimum of $5 \times 10^{4} \mathrm{cpm}$ was applied to each plate. In all cases two spikes minus the awns served as starting material, and $15.65 \mu \mathrm{C}$ were used except for the second ${ }^{3} \mathrm{H}$ experiment when $62.6 \mu \mathrm{C}$ were fed. For the latter the values given are $1 / 4$ of those observed.

n.d. = not detected

marked stimulation of aldehyde and ester synthesis (Table I). The extent of this increase, especially for the aldehydes, was somewhat variable as shown by the four independent replicates with myristate.

The distribution of label among the three cer-c $c^{36}$ ester moieties, namely fatty acids, alkan1-ols and alkan-2-ols, after feeding various labelled precursors is presented in Table II. Labelling of all moieties occurred when $\mathrm{C}_{2}, \mathrm{C}_{12}$ and $\mathrm{C}_{14}$ fatty acids were fed. Alkan-2-ols were not labelled when ( $1-$ or $\left.2-{ }^{14} \mathrm{C}\right)-\mathrm{C}_{16}$ or $\left(1-{ }^{14} \mathrm{C}\right)-\mathrm{C}_{18}$ acid was fed but were so when the $\left(9,10-{ }^{3} \mathrm{H}\right)-\mathrm{C}_{\mathrm{i}}$ acid was (32). This is in accord with the results of a more recent investigation of the biosynthetic origin of alkan-2-ols (22). That is, a $\mathrm{C}_{16}$ acid or its CoA derivative can serve as a precursor of a labelled $\mathrm{C}_{15}$-2-ol if it is first converted to a $\mathrm{C}_{14}$ acid which is then elongated by addition of a $\mathrm{C}_{2}$-unit to give the mandatory 3-oxoacyl $\mathrm{C}_{16}$ percursor. Such a scheme necessitates among other enzymes, for example, an active decarboxylase which is known to exist in the barley spike minus awn tissue slice system (22). Of the $C_{16}$ percursors studied only the internally labelled ${ }^{3} \mathrm{H}$-one retains its label during the specified sequence of reactions. The small amount of label in the alkan-2-ols in the first ${ }^{3} \mathrm{H}-\mathrm{C}_{\mathrm{I}}$ acid experiment given in Table II is equivalent to that observed when $10.8 \mu \mathrm{C}$ of $\left(9,10-{ }^{3} \mathrm{H}\right)-\mathrm{C}_{16} \mathrm{CoA}$ with a specific activity of $61.2 \mathrm{mCi} \cdot \mathrm{mmol}^{-1}$ was used as a percursor (22). The much more extensive labelling of the alkan-2-ols in the second ${ }^{3} \mathrm{H}-\mathrm{C}_{16}$ acid experiment given in Table II is presumably due to the fact that four times as much labelled substrate was fed as in the first experiment. Since both experiments were carried out with the same batch of precursor, one can not attribute the higher labelling to a ${ }^{3} \mathrm{H}-\mathrm{C}_{14}$ acid contaminant as has been done (22).

The stimulation of ester synthesis by tissue slices fed the longer fatty acids noted in Table I, is shown by the data of Table II to result primarily from increased incorporation of label into the fatty acid moiety of the esters. For the present study, however, the six to nine fold increase in conversion of $C_{14}$ and $C_{12}$ vs $C_{2}$ acids into alkan-2-ols is of greater interest. With the two longer precursors, sufficient label is present in the esterified alkan-2-ols of the wax of tissue slices from two spikes minus awns not only to allow their isolation and analyses but also to 
Table III.

Effect of pretreatments with $\mathrm{ME}$ on incorporation of $\left(1-{ }^{14} \mathrm{C}\right)$-laurate into five epicuticular lipid fractions by tissue slices prepared from cer-c $^{36}$ spikes minus the awns $\left(\mathrm{cpm} \times 10^{-4}\right)^{2}$.

\begin{tabular}{llllll}
\hline \multirow{2}{*}{$\begin{array}{l}\mathrm{ME}^{\mathrm{b}} \\
(\mathrm{mM})\end{array}$} & Aldehyde & Acid & Alkan-1-ol & Alkan-2-ol & Hydrocarbon \\
\hline 0 & 4.5 & 33.0 & 3.2 & 6.4 & 2.2 \\
0.1 & 4.3 & 39.3 & 3.2 & 6.7 & 2.1 \\
10 & 13.1 & 44.4 & 2.7 & 5.6 & 0.2 \\
\hline
\end{tabular}

a Lipid fractions were separated and quantitated as described in the footnotes a of Tables I and II except that ${ }^{14} \mathrm{C}$ distributions among the esters' moieties were obtained by triangulation.

${ }^{b}$ Pretreatment for 30 minutes followed by 99 -fold dilution and addition of $15.65 \mu \mathrm{C}$ substrate. Incorporation time was three hours. Two spikes minus the awns served as starting material in all cases.

permit a study of the effect of pretreatments with selected inhibitors on their synthesis.

\subsection{Effects of pretreatments with inhibitors on incorporation of labelled substrates into wax lipid fractions}

Table III presents the results of an experiment in which tissue slices of $c e r-c^{36}$ spikes minus awns were exposed to varying concentrations of $\mathrm{ME}$ for 30 minutes before $C_{12}$ acid was added. The highest concentration of ME tested had no effect on labelling of the three ester moieties while greatly inhibiting that of the hydrocarbons. The same distribution of label was observed for the 1
mM ME experiment as that presented for $10 \mathrm{mM}$ ME. The effects of preincubations with AS on the incorporation of $\mathrm{C}_{14}$ acid into tissue slice waxes of both $c e r-c^{36}$ and $-q^{42}$ are shown in Table IV. Unlike cer-c $^{36}$ of which it is an allele, the mutant cer- $q^{42}$ is unable to synthesize alkan-2-ol containing esters (31). In contrast to $\mathrm{ME}, \mathrm{AS}$ within the concentration range tested severely inhibited alkan-2-ol synthesis. While an effect is also seen on the hydrocarbons, it is not so drastic, as even with $10 \mathrm{~mm}$ AS some hydrocarbons were synthesized while the alkan-2-ols were already absent after a $1 \mathrm{mM}$ treatment. The same relative effects were seen when AS treatment was followed by $\left(1-{ }^{14} \mathrm{C}\right)-\mathrm{C}_{2}$ acid feeding. The observed

Table IV.

Effect of pretreatments with AS on incorporation of $\left(1{ }^{14} \mathrm{C}\right)$-myristate into five epicuticular lipid fractions by tissue slices from cer-c $c^{36}$ and $-q^{62}$ spikes minus the awns $\left(\mathrm{cpm} \times 10^{-1}\right)^{2}$.

\begin{tabular}{cccccc}
\hline \multirow{2}{*}{$\begin{array}{l}\text { AS } \\
(\mathrm{mM})\end{array}$} & Aldehyde & Acid & Alkan-1-ol & Alkan-2-ol & Hydrocarbon \\
\cline { 5 - 6 } cer-c $^{36}$ & & & & & \\
0 & 10.8 & 19.4 & 1.2 & 3.5 & 1.0 \\
0.1 & 37.9 & 21.5 & 1.2 & & 0.4 \\
10 & 13.7 & 15.8 & 0.7 & & 0.1 \\
${\text { cer- } q^{42}}_{0}$ & 12.8 & 18.9 & 2.1 & & 0.6 \\
1.0 & 3.5 & 17.3 & 1.0 & & 0.04 \\
\hline
\end{tabular}

${ }^{a}$ Lipid fractions were separated and quantitated as described in the footnotes a of Tables I and II except that ${ }^{14} \mathrm{C}$ distributions among the esters' moieties were obtained by triangulation of peaks visible in the radio thin layer chromatographic traces. See footnote $b$ Table III for experimental conditions. 
Table V.

Effect of pretreatments with $\mathrm{CN}$ on incorporation of $\left(1{ }^{14} \mathrm{C}\right)$-substrates into three lipid classes by tissue slices from $c e r-c^{36}$ spikes minus the awns $\left(\mathrm{cpm} \times 10^{-4}\right)^{2}$.

\begin{tabular}{|c|c|c|c|c|c|}
\hline Substrate & $\begin{array}{l}\text { Time } \\
\text { (hours) }\end{array}$ & $\begin{array}{l}\mathrm{CN} \\
(\mathrm{mM})\end{array}$ & Aldehyde & Ester & Hydrocarbon \\
\hline \multirow[t]{5}{*}{ Acetate } & \multirow[t]{3}{*}{6} & 0 & 5.5 & 17.9 & 4.1 \\
\hline & & 0.01 & 15.8 & 41.9 & 14.3 \\
\hline & & 0.1 & 5.7 & 26.5 & 3.1 \\
\hline & \multirow[t]{2}{*}{3} & 0 & 1.9 & 9.6 & 2.1 \\
\hline & & 0.1 & 0.9 & 4.4 & 0.5 \\
\hline \multirow[t]{3}{*}{ Laurate } & \multirow[t]{3}{*}{6} & 0 & 3.6 & 29.5 & 2.5 \\
\hline & & 0.01 & 10.2 & 54.6 & 5.7 \\
\hline & & $0.1^{\mathrm{b}}$ & 11.5 & 15.9 & 2.0 \\
\hline \multirow[t]{5}{*}{ Myristate } & \multirow[t]{3}{*}{6} & 0 & 26.0 & 52.1 & 1.9 \\
\hline & & 0.01 & 53.8 & 39.4 & 1.6 \\
\hline & & 0.1 & 28.2 & 49.7 & 2.2 \\
\hline & \multirow[t]{2}{*}{3} & 0 & 13.3 & 26.8 & 1.5 \\
\hline & & 0.1 & 16.7 & 29.0 & 0.3 \\
\hline \multirow[t]{3}{*}{ Palmitate } & \multirow[t]{3}{*}{6} & 0 & 33.8 & 86.4 & 5.5 \\
\hline & & 0.01 & 146.7 & 46.0 & 3.2 \\
\hline & & 0.1 & 134.6 & 64.4 & 1.6 \\
\hline
\end{tabular}

relative sensitivities of alkan-2-ol and hydrocarbon synthesis by tissue slices pretreated with ME and AS are analogous to those reported earlier for $\beta$-diketones and hydrocarbons, respectively, when whole spikes of $c e r-u^{69}$ and $\left(2-{ }^{14} \mathrm{C}\right)-\mathrm{C}_{2}$ acid were used (23).

Summarized in Table $\mathrm{V}$ are the effects of pretreatments with $\mathrm{CN}$ on the incorporation of four different $\left(1-{ }^{14} \mathrm{C}\right)$-fatty acids into three lipid classes. When the results of the three vs six hours of incorporation for the $\mathrm{C}_{2}$ vs $\mathrm{C}_{14}$ acid control experiments are compared, higher amounts of label were incorporated with the longer time except in the case of the hydrocarbons labelled with $\mathrm{C}_{14}$-acid. A similar comparison for the $\mathrm{C}_{12}$ acid(Table III vs I and $\mathrm{V}$, respectively) reveals no such differences, however. Since a consistent decrease in amount of label in the lipids of interest did not occur with a halving of the incorporation time, three hours has been most frequently used in these studies.

In the six hour experiments in which $\mathrm{C}_{2}$ and $\mathrm{C}_{12}$ acids served as the labelled precursors, both ester and hydrocarbon syntheses were stimulated by pretreatment with the lower $\mathrm{CN}$ concentration $(0.01 \mathrm{mM})$, whereas the higher concentration $(0.1 \mathrm{mM})$ appeared to have no effect (Table V). An analogous stimulation of hydrocarbon and even chain length wax fraction syntheses was observed when $\mathrm{CN}$ preincubations were followed by $\left(2-{ }^{14} \mathrm{C}\right)-\mathrm{C}_{2}$ acid feeding to whole spikes of cer- $u^{69}(20,23)$. Pretreatments with 1 and $10 \mathrm{mM} \mathrm{CN}$ resulted in marked inhibition of hydrocarbon synthesis with both presursors fed for six hours. When only three hours were allowed for incorporation of the labelled $\mathrm{C}_{2}$ acid (Table V), a marked decrease in hydrocarbon and ester synthesis occurred already with $0.1 \mathrm{mM} \mathrm{CN}$ pretreatments. This suggests that the inhibitory effect of $\mathrm{CN}$ pretreatments can be overcome when a long enough time for wax synthesis is permitted thereafter.

Allowing six hours for incorporation of the longer $\mathrm{C}_{14}$ and $\mathrm{C}_{16}$ acids after $\mathrm{CN}$ preincubation, in contrast to the shorter fatty acids, did not lead to a stimulation of ester and hydrocarbon syn- 
Table VI.

Effect of a 30 minute pretreatment with $\mathrm{CN}$ on \% distribution of ${ }^{14} \mathrm{C}$ among the alcohol moieties of esters labelled during six hours with $15.65 \mu \mathrm{C}$ of various $\left(1-{ }^{14} \mathrm{C}\right)$-substrates by tissue slices prepared from $c e r-c^{36}$ spikes minus the awns".

\begin{tabular}{|c|c|c|c|c|c|c|}
\hline \multirow{2}{*}{$\begin{array}{l}\mathrm{CN} \\
(\mathrm{mM})\end{array}$} & \multicolumn{2}{|c|}{ Acetate $^{b}$} & \multicolumn{2}{|c|}{ Laurate } & \multicolumn{2}{|c|}{ Myristate } \\
\hline & 1-ol & 2-ol & $1-\mathrm{ol}$ & 2-ol & $1-\mathrm{ol}$ & 2-ol \\
\hline 0 & 63 & 37 & 32 & 68 & 35 & 65 \\
\hline 0.1 & 70 & 30 & 36 & 64 & 50 & 50 \\
\hline 1.0 & & & 82 & 18 & 46 & 54 \\
\hline 10 & & & 96 & 4 & 91 & 9 \\
\hline
\end{tabular}

a Esters and their moieties were isolated and quantitated as described in footnotes a of Tables I and II. See footnote $b$ Table III for experimental conditions.

b Too little label was recovered in the wax to obtain results from the 1 and $10 \mathrm{~mm}$ experiments.

thesis (Table V). The only noticable effect was a decrease in labelled hydrocarbons as the amount of $\mathrm{CN}$ increased to $0.1 \mathrm{mM}$ when $\mathrm{C}_{16}$ fatty acid was the precursor. As with the shorter precursors 1 and $10 \mathrm{mM} \mathrm{CN}$ pretreatments greatly reduced hydrocarbon synthesis. Likewise, reducing the time allowed for incorporation of acid to three hours resulted in less labelling of hydrocarbons although not of the esters. At least in terms of hydrocarbon synthesis therefore, the same difference, and presumably for the same reason noted above, between the three and six hour incorporations following $\mathrm{CN}$ pretreatments occurred. From the data presented one can conclude that while $\mathrm{CN}$ interferes with hydrocarbon synthesis this effect is only detectable under specified experimental conditions.

To verify the possible effect of $\mathrm{CN}$ preincubations on ester synthesis, the individual ester moities were examined. Table VI presents the relative amounts of label found in the two types of alcohols when $\mathrm{CN}$ pretreatment was followed by six hour incubations. A clear inhibition of alkan-2-ol synthesis is revealed when either $C_{12}$ or $\mathrm{C}_{14}$ acids served as substrates. Alkan-1-ol synthesis is, however, not immune to $\mathrm{CN}$ pretreatments. For example, the cpm $\times 10^{-4}$ incorporated from the $\mathrm{C}_{14}$ acid into this ester moiety decreased from 2.2 in the control experiment to 1.2 after $1 \mathrm{mM}$ treatment and to 0.7 after $10 \mathrm{mM}$ treatment. The $\mathrm{C}_{2}$ acid experiment gave no results, but illustrates the conclusion drawn at the end of section 3.1 , namely that $\left(1-{ }^{14} \mathrm{C}\right)-\mathrm{C}_{2}$ acid does not label the alkan-2-ols well enough to permit these types of studies unless the experimental parameters are considerably scaled up. The experimental results detailed thus far fail to reveal a marked difference in sensitivity of alkan-2-ol and hydrocarbon syntheses to $\mathrm{CN}$ pretreatments. This was unexpected as previous studies with whole spikes of $c e r-u^{69}$ fed $\left(2-{ }^{14} \mathrm{C}\right)-\mathrm{C}_{2}$ acid showed that $\beta$-diketone biosynthesis is considerably more sensitive to $\mathrm{CN}$ pretreatments than is that of the hydrocarbons and all the other wax lipids $(20,23)$. Namely, the former is already greatly inhibited at $\mathrm{CN}$ concentrations stimulating the others.

Figure 1. Radio-gas chromatographic separations of esters synthesized from $\left(1-{ }^{14} \mathrm{C}\right)$-substrates during six hours by tissue slices prepared from $c e r-q^{42}$ and $-c^{36}$ spikes minus the awns. Arabic figures give chain lengths of alkan-1-ol esters, circled figures give chain lengths of alkan-2-ol esters and small letters indicate esters of $\mathrm{C}_{12}-\mathrm{C}_{24}$ acids esterified with various alcohol moiety(ies), see section 3.3. The * indicates the position that di-2-ethylhexylphthalate elutes (approx. $210^{\circ} \mathrm{C}$ ) while the $\mathrm{C}_{52}$ ester elutes at approx. $340^{\circ} \mathrm{C}$. The procedure for isolation of the esters is described in section 2.2. Approx. $1.1-3.1 \times 10^{4} \mathrm{cpm}$ were injected per chromatogram. 
P. voN WeTtSTEIN-KnOWLes: Synthesis of esterified alkan-2-ols
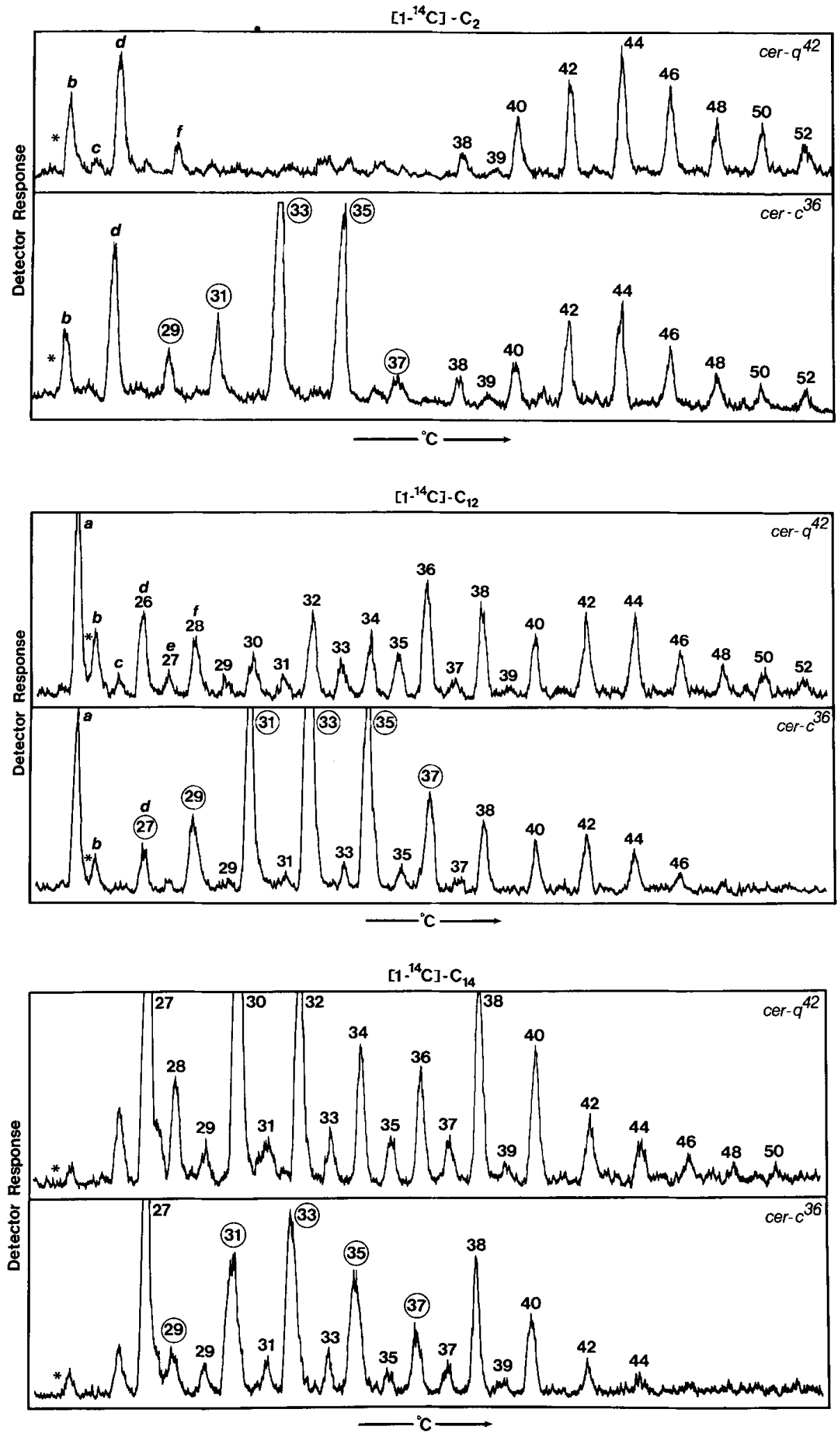


\subsection{Isolation of labelled esters and their identification}

In addition to splitting the esters into their component moieties to study the effect of inhibitors on ester synthesis, the esters can be analyzed by radio-GC. Figure 1 presents the traces obtained after feeding $\left(1-{ }^{14} \mathrm{C}\right)-\mathrm{C}_{2},-\mathrm{C}_{12}$ and $-\mathrm{C}_{14}$ acids to tissue slices prepared from spikes minus awns of $c e r-c^{36}$ and $-q^{42}$. Feeding $C_{2}$ acid (Figure 1 top) results in radioactive distributions similar in several aspects to the respective in vivo compositions (36). That is, among the $\mathrm{C}_{38}-\mathrm{C}_{52}$ alkan-1-ol esters those with 42 to 46 carbons dominate, and the $\mathrm{C}_{29}-\mathrm{C}_{37}$ alkan-2-ol esters are synthesized only by the $c e r-c^{36}$ tissue slices. The spectrum of the latter esters, however, is shifted making the shorter chain lengths much more prominent. Both traces furthermore reveal the presence of several unknown components (labelled with letters) for which corresponding peaks were absent in the mass traces. Analogous peaks are likewise unknown from compositional analyses of esters (36).

Feeding the $\mathrm{C}_{12}$ and $\mathrm{C}_{14}$ acids (Figure 1 middle and bottom, respectively) gave quite different radioactive traces from that obtained after $\mathrm{C}_{2}$ acid feeding (Figure 1 top). The ability to synthesize the longer chain alkan-1-ol esters diminished, especially in $c e r-c^{36}$ tissue slices, while the shorter ones, most dramatically $\mathrm{C}_{38}$, became very prominent. In the temperature range in which the alkan-2-ol esters eluted in cer- $^{36}$ traces, many unexpected radioactive peaks are seen in the $c e r-q^{42}$ traces. These in fact dominate the spectrum when $\mathrm{C}_{14}$ acid was fed. These have been tentatively identified as alkan-1-ol esters of the chain lengths noted on the traces in Figure 1 middle and bottom on the basis of their elution temperatures from gas chromatographic columns compared to standards. None of the results presented elsewhere in this paper contradict these assignments. The $\mathrm{C}_{12}$ acid is incorporated into a number of short unknowns by tissue slices from both genotypes, whereas the $C_{14}$ acid is not with the notable exception of the peak labelled 27.

The complexity revealed by the radio-gas chromatographic traces in Figure 1 of the isolated esters requires that the nature of the unexpectedly synthesized esters must be determined if data of the type presented in Tables I-V is to be accurately evaluated. To accomplish this labelled waxes from ten replicate experiments of $c e r-c^{36}$ tissue slices fed $\mathrm{C}_{2}, \mathrm{C}_{12}$ or $\mathrm{C}_{14}$ acids were pooled. Specific activities were 58.1, 32.0 and $55.0 \mathrm{mCi} \cdot \mathrm{mmol}^{-1}$, respectively. Radio-thin layer chromatographic traces obtained from single experiments, such as the data in Tables I-VI are based upon, can be compared in Figure $2 \mathrm{~A}-\mathrm{C}$, with those from the pooled experiments (Figure 2 D-F). Since the peak corresponding to the esters from the pooled $\mathrm{C}_{2}$ acid feeding experiment (Figure 2D) appeared to be composed of two overlapping components, the silica gel from the two halves of the ester peak was eluted separately and designated Est I and Est II. A radio-gas chromatographic separation of the Est I components is presented in the upper half of Figure 3. A comparison with the appropriate trace in Figure 1 (second from top) reveals that Est I contains the shortest components of the total ester fraction, namely the short unknowns plus a small amount of alkan-2-ol esters. This is the expected result as short esters are less mobile than long esters in the thin layer chromatographic system used. Preparative radio-GC was then carried out and the peaks labelled $a$ to $f$ were collected as a group. An identical series of experiments were performed to obtain the esters designated $a$ to $f$ from tissue slices of cer- $q^{42}$ fed $C_{2}$ acid. As illustrated in Figure $2 \mathrm{E}$ a partial resolution of the shorter vs longer ester components was not obtained by radio-TLC after feeding $\mathrm{C}_{12}$ acid to tissue slices of $c e r-c^{36}$ or $-q^{42}$. Esters eluting in the temperature range of $a$ to $f$, therefore, had to be collected by preparative radio-GC of the total esters.

The unknown peaks $a$ to $f$ were transesterified. Radio-TLC of the products gave essentially one labelled peak that cochromatographed with a fatty acid methyl ester standard. Injection of the fatty acid methyl esters into the radio-gas chromatograph resulted in the distributions presented in Table VII. After feeding either precursor, most of the label was recovered in $C_{20}$ and $C_{18}$ acids. While the majority of the $C_{12}$ acid precursor was elongated before being incorporated into the esters, some was directly esterified as revealed by the detection of approx. $10 \%$ of the label in $\mathrm{C}_{12}$ acids. Whether or not the 


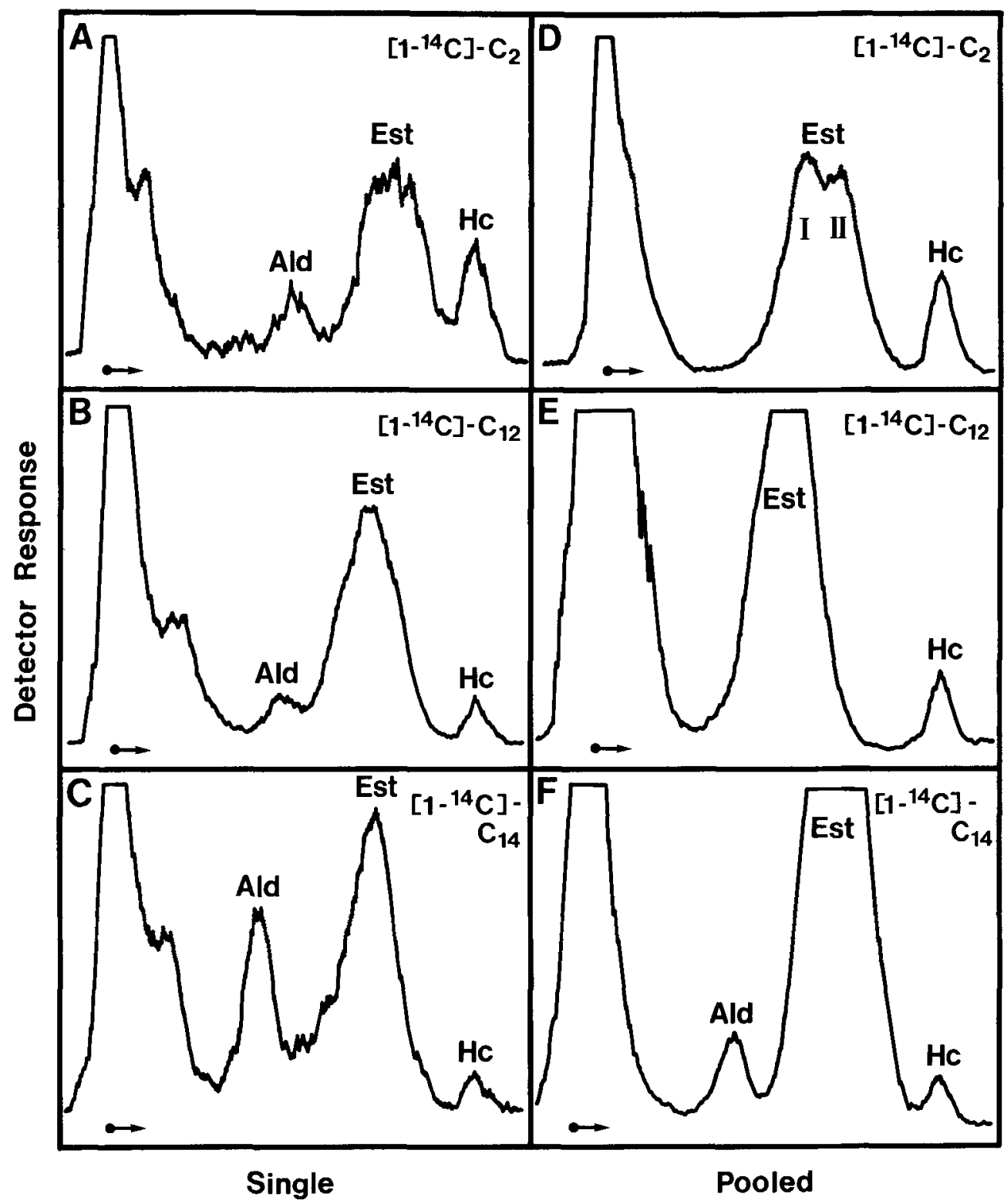

Figure 2. Radio-thin layer chromatographic separations of wax lipids synthesized during three hours from $\left(1-{ }^{14} \mathrm{C}\right)$-substrates by tissue slices prepared from $c e r-c^{36}$ spikes minus the awns. A, B and C represent typical patterns obtained from single experiments utilizing $15.65 \mu \mathrm{C}$ and two spikes as starting material (see Table I). $D, E$ and $F$ represent the patterns obtained from the 10 pooled, single experiments carried out to yield sufficient esters (Est) for identification of short unknown esters. From D the esters designated I and II were recovered separately from the thin layer chromatographic plates (see Figure 3 upper). In D and E the aldehydes (Ald) were not separated from the esters, but were shown to be present in minor amounts as primary alcohols after $\mathrm{NaBH}_{4}$ reduction. In $\mathrm{F}$ the esters synthesized (see Figure 3 lower) were not those expected (see Figure 1 lower). $\leftrightarrow$ indicates the origin and direction of separation. The resolution of the hydrocarbons $(\mathrm{Hc})$ and esters varies according to whether only benzene or first hexane and then benzene was used as the developing solvents plus the distance(s) the solvent(s) moved, the thickness of the gel and the chain lengths of the esters synthesized. 


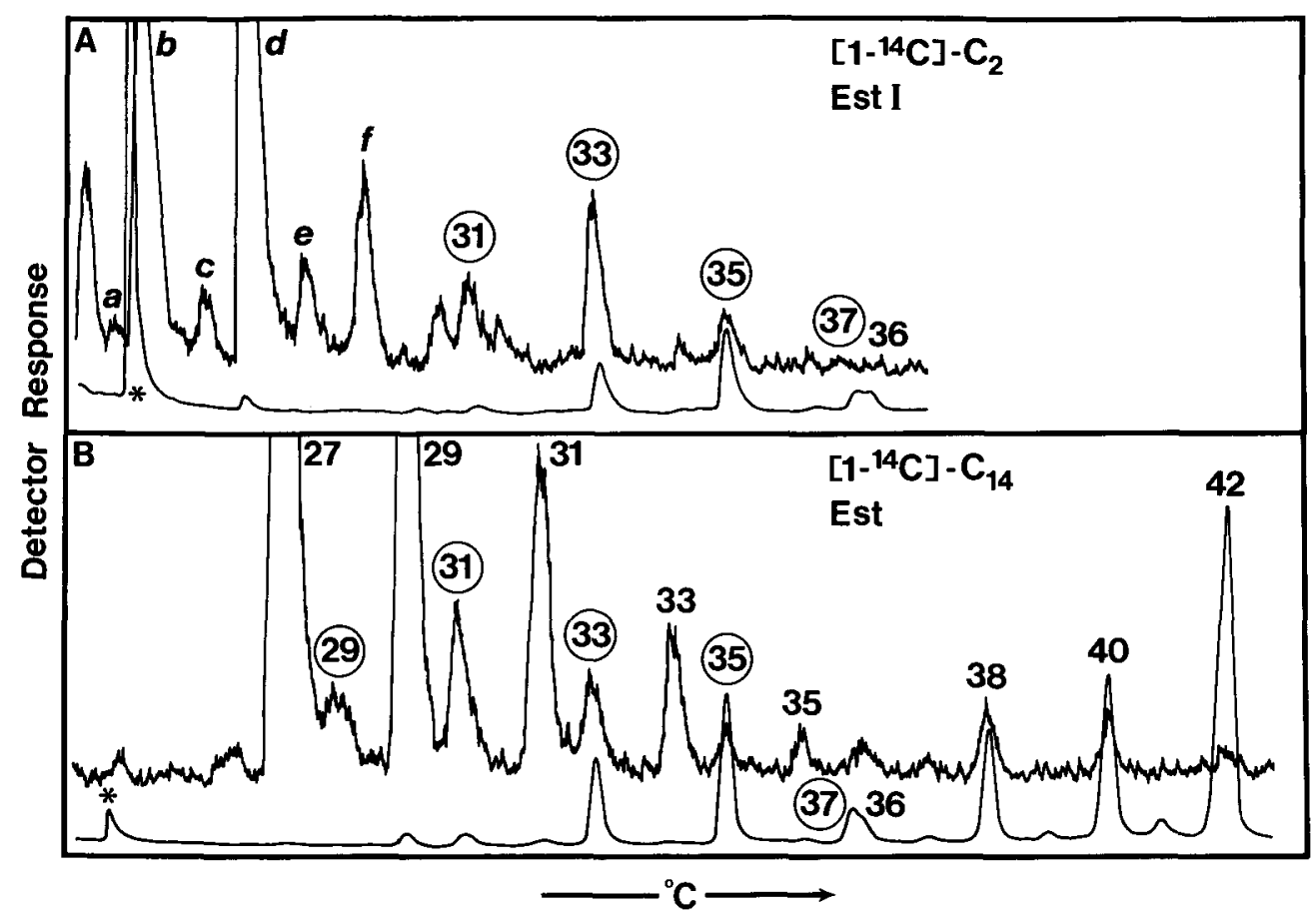

Figure 3. Radio-gas chromatographic separations of esters synthesized by $c e r-c^{36}$ spikes minus the awns that were isolated from the pooled experiments $D$ and $F$ in Figure 2 and used for collecting via preparative GC (section 2.4) of unknowns. In A the peaks marked $a-f$ were collected as a group, whereas in B the peaks marked 27, 29 and 31 were collected separately. Arabic figures are alkan-1-ol esters, circled figures are alkan-2-ol esters and $a-f$ represent esters with $\mathrm{C}_{16}-\mathrm{C}_{22}$ fatty acids esterified to unknown alcohol moiety(ies). The ${ }^{*}$ identifies di-2-ethylhexylphthalate, an internal standard visible in the mass traces.

differences in distributions between the two genotypes are significant is unknown. Some of the variation may well have been introduced during the radio-gas chromatographic trapping process.
An examination of the elution profile of the short unknowns labelled by $\mathrm{C}_{2}$ acid (Figure 1 upper) suggests that peaks $b, d$ and $f$ form a homologous series whose members differ by two carbons in length. This is in accord with the

Table VII.

Distribution of ${ }^{14} \mathrm{C}$ among the acid moieties of the trapped short esters $(\%)$.

\begin{tabular}{llllllll}
\hline \multirow{2}{*}{$\begin{array}{l}\text { Substrate } \\
\left(1-^{14} \mathrm{C}\right)-\end{array}$} & cer- & 12 & 14 & 16 & 18 & 20 & 22 \\
\hline \multicolumn{1}{l}{ Acetate } & $c^{36}$ & & & 2.9 & 23.6 & 59.0 & 14.5 \\
& $q^{42}$ & & & & 47.2 & 48.4 & 4.4 \\
Laurate & $c^{36}$ & 7.6 & 1.3 & 4.6 & 36.7 & 49.3 & 0.6 \\
& $q^{42}$ & 11.0 & 1.4 & 2.8 & 44.9 & 37.6 & 2.3 \\
\hline
\end{tabular}

a The short esters designated $a-f$, as illustrated in Figures $3 \mathrm{~A}$ and 1 (upper and middle), were collected by preparative GC and transesterified as described in sections 2.4 and 2.3. The resulting acid moieties as their methyl esters were isolated from thin layer chromatographic plates developed in benzene and subjected to radio-GC. Distributions are based upon $0.8-2.7 \times 10^{4} \mathrm{cpm}$. 
observed acid moiety distributions (Table VII). Although insufficient label after $\left(1-{ }^{14} \mathrm{C}\right)-\mathrm{C}_{2}$ acid feeding was present in the alcohol moieties to allow their identification, they are presumably quite short. For example, since peak $d$ elutes very nearly at the same temperature as a $\mathrm{C}_{26}$ ester and its fatty acid moieties have 18,20 and/or 22 carbons, the alcohol moieties if primary can only have 8,6 or 4 carbons. In vivo very short acid moieties of long chain esters have been reported a number of times; for example, esters of acetic and propionic acids serve as sex pheromones in pine sawflies (15), of acetic, acetoacetic and hydroxybutyric acids are present in the cuticle wax of tobacco hornworm pupae (5), of acetic acid occur in the leaf wax of the dicotyledon Chenopodium album (1), and of $\mathrm{C}_{2},{ }_{5,7}$ and ${ }_{8}$ acids are found in the surface wax of the crustacean Ligia oceanica (9). Interestingly, in the latter long chain esters of $\mathrm{C}_{5}$, ${ }_{6}$ and 7 primary alcohols have also been reported. A presumably analogous series of labelled short chain esters was detected after feeding $\left(2-{ }^{14} \mathrm{C}\right)-\mathrm{C}_{2}$ acid to intact $c e r-u^{69}$ spikes (20). In contrast to the present results, however, the acid moieties had a different distribution than those of the long chain alkan-1-ol and alkan-2-ol esters.

A comparison of Figure $2 \mathrm{C}$ and $\mathrm{F}$ reveals that the esters were more efficiently labelled by $\mathrm{C}_{14}$ acid in the pooled experiments than in the single experiment. Recovery from thin layer plates of esters from the pooled experiments and injection into the radio-gas chromatograph gave the unexpected result depicted in the bottom half of Figure 3. Very little label is present in the alkan-1-ol and alkan-2-ol esters, while most is in three very early eluting components, the first of which corresponds to the unknown labelled 27 in the two bottom traces of Figure 1. An identical radioactive spectrum was obtained for the esters synthesized by cer- $q^{42}$ tissue slices. By preparative radio-GC the three unexpected peaks labelled 27, 29 and 31 (Figure 3 bottom) were collected separately. In contrast to the short unknown esters designated $a$ to $f$, after transesterification all label was recovered in acid moieties. Radio-GC of the latter revealed that for both genotypes the only labelled acid moiety from peak 27 had 14 carbons, that from peak 29 had 16 carbons and that from peak 31 had

$$
\mathrm{CH}_{3}-\left(\mathrm{CH}_{2}\right)_{11}-\mathrm{CH}_{2}-\mathrm{OH}
$$

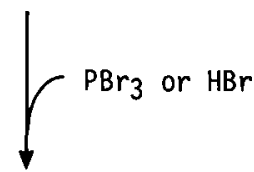

II

$$
\mathrm{CH}_{3}-\left(\mathrm{CH}_{2}\right)_{11}-\mathrm{CH}_{2}-\mathrm{Br}
$$

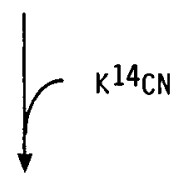

III

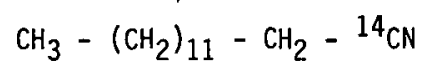

IV

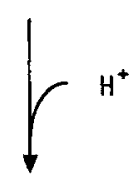

Figure 4. Pathway used by Applied Science Laboratories for the chemical synthesis of $\left(1-{ }^{14} \mathrm{C}\right)$-myristic acid (IV) from tridecanol (I) via tridecylbromide (II) and myristonitrile (III) with label coming from potassium cyanide $\left(\mathrm{K}^{14} \mathrm{CN}\right)$.

18 carbons. If these three acids were esterified to $\mathrm{C}_{13}-1$-ols, $\mathrm{C}_{27},{ }_{29}$ and ${ }_{31}$ esters would result. That the three unexpected peaks (Figure 3 bottom) might indeed be attributable to $\mathrm{C}_{27}, 29$ and ${ }_{31}$ esters is supported by the observation that they elute at the expected temperature for such esters from the gas chromatographic columns used.

Given that the three unexpected peaks represent the designated esters, the question of interest is the source of the $\mathrm{C}_{13}-1-\mathrm{ol}$. One possibility is substrate contamination as diagrammed in Figure 4. Since the first reaction in this pathway does not go to completion (8), the unreacted $\mathrm{C}_{13}$-1-ol (I) has to be removed if a pure final product $\left(1-{ }^{14} \mathrm{C}\right)-\mathrm{C}_{14}$ acid (IV) is desired. To test the hypothesis that the labelled $\left(1-{ }^{14} \mathrm{C}\right)-\mathrm{C}_{14}$ acid used as substrate for the pooled experiments contained $\mathrm{C}_{13}-1$-ol which was being esterified to the labelled $\mathrm{C}_{14}$ acid and its elongation products, namely $C_{16}$ and $C_{18}$ acids, the following experiment was carried out. Tissue slices pre- 
Table VIII.

Effect of tridecan-1-ol on the synthesis of esters from $10 \mu \mathrm{C}$ of $\left(1-^{14} \mathrm{C}\right)$-palmitic acid by tissue slices prepared from $c e r-q^{42}$ spikes minus the awns $\left(\mathrm{cpm} \times 10^{-4}\right)^{\circ}$.

\begin{tabular}{|c|c|c|c|c|c|c|c|c|c|c|}
\hline \multirow{2}{*}{$\begin{array}{l}C_{13}-1-o l \\
(\mu g)\end{array}$} & \multicolumn{10}{|c|}{ Number of carbons } \\
\hline & 29 & 31 & 33 & 38 & 39 & 40 & 42 & 44 & 46 & 48 \\
\hline 0 & 0.4 & 1.6 & & 2.4 & 0.9 & 9.1 & 6.6 & 1.3 & 1.5 & 1.4 \\
\hline 150 & 97.3 & 10.0 & 2.0 & 0.8 & & 4.2 & 3.6 & 1.2 & 0.5 & \\
\hline
\end{tabular}

awo spikes minus the awns in $10 \mathrm{ml}$ of glass distilled water served as starting material in both cases. After three hours, $300 \mu \mathrm{l} 10 \mathrm{~N} \mathrm{H}_{2} \mathrm{SO}_{4}$ was added and the lipids extracted with $30 \mathrm{ml}$ of chloroform. The esters were isolated by radio-TLC and quantitated by radio-GC as described in sections 2.2 and 2.4. Experiment courtesy Dr. J.D. MikKelseN.

pared from spikes minus awns of $c e r-q^{42}$ were presented with $45.7 \mu \mathrm{g}$ of $\left(1-{ }^{14} \mathrm{C}\right)-\mathrm{C}_{16}$ acid plus $0,15,30$ or $150 \mu \mathrm{g}$ of $\mathrm{C}_{13}-1$-ol. The data in Table VIII confirm the hypothesis and demonstrate that the presence of an unlabelled alcohol such as $\mathrm{C}_{13}-1$-ol will distort normal ester synthesis in precisely the manner shown in Figure 3 bottom. In an analogous fashion addition of increasing amounts of hexadecanol to a soluble fas from etiolated Euglena was found to both stimulate ester synthesis and to markedly modify their chain length distribution (17).

One is led to deduce that the batches of $\left(1-{ }^{14} \mathrm{C}\right)-\mathrm{C}_{14}$ used in the studies described herein contained varying small amounts of unlabelled $\mathrm{C}_{13}$-1-ol, except for the batch from Applied Science Laboratories which was used for the pooled experiments that contained a much larger amount. This variability offers an explanation not only for the difference in radio-gas chromatographic patterns of the esters synthesized (e.g., Figure 1 bottom vs Figure 3 bottom), but also for the variable amounts of esters labelled (e.g., Figure $2 \mathrm{C}$ vs 7 and Table I) when different batches of precursor were used.

By analogy to the above results the short unknown labelled $a$ in Figure 1 middle must be a $\mathrm{C}_{23}$ ester. That is the $\left(1-{ }^{14} \mathrm{C}\right)-\mathrm{C}_{12}$ acid substrate contained some $\mathrm{C}_{11}-1-\mathrm{ol}$. In support of this proposal are the observations that upon transesterification of peaks $a$ to $f$ (Figure 1 middle) a labelled $C_{12}$ acid moiety was recovered (Table VII), that peak $a$ eluted at the temperature expected for the designated $C_{23}$ ester and that peak $a$ 's size varied with the batch of substrate being used.

\subsection{Effects of pretreatments with inhibitors on incorporation of labelled precursors into wax esters}

From the data in Table IV the conclusion was drawn that treatments with ME had no effect on the total or relative amounts of $\left(1-{ }^{14} \mathrm{C}\right)$ $\mathrm{C}_{12}$ subsequently incorporated into the three ester moieties by tissue slices prepared from $c e r-c^{36}$ spikes minus awns. Examination of these same esters by radio-GC (Table IX), however, revealed that the chain length of the alkan-2-ol esters being synthesized had been markedly affected by the two higher ME concentrations. The increase of the shorter alkan-2-ol esters at the expense of the longer ones implies that an elongation system is being impaired by ME. By comparison elongation of both types of esters in the control is somewhat less efficient than in the experiment shown in Figure 1 middle.

The effects of exposure to AS and $\mathrm{CN}$ on the $c^{2}-c^{36}$ synthesized ester distributions are given in Tables X and XI. Since data presented earlier led to the deduction that alkan-2-ols are synthesized poorly if at all after AS treatment, the present distributions must be based upon label in the acid and alkan-1-ol moieties. Table $\mathrm{X}$ shows that when $\mathrm{C}_{2}$ acid served as the labelled precursor the low concentration of AS tested appeared without effect except for a possible increase in the presumed $\mathrm{C}_{29}$-2-ol ester. Some- 
P. VON WETTSTEIN-KNOWLES: Synthesis of esterified alkan-2-ols

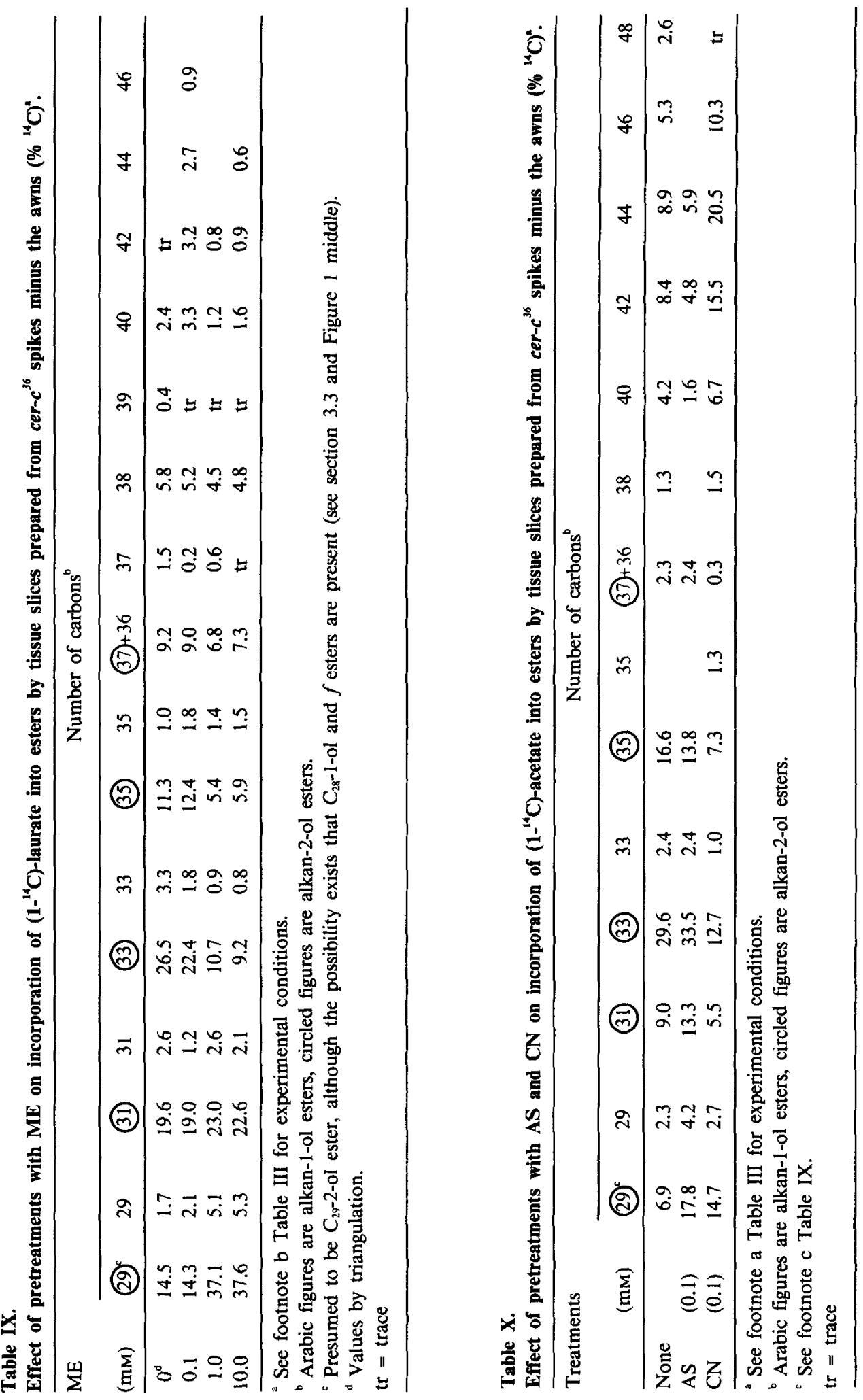




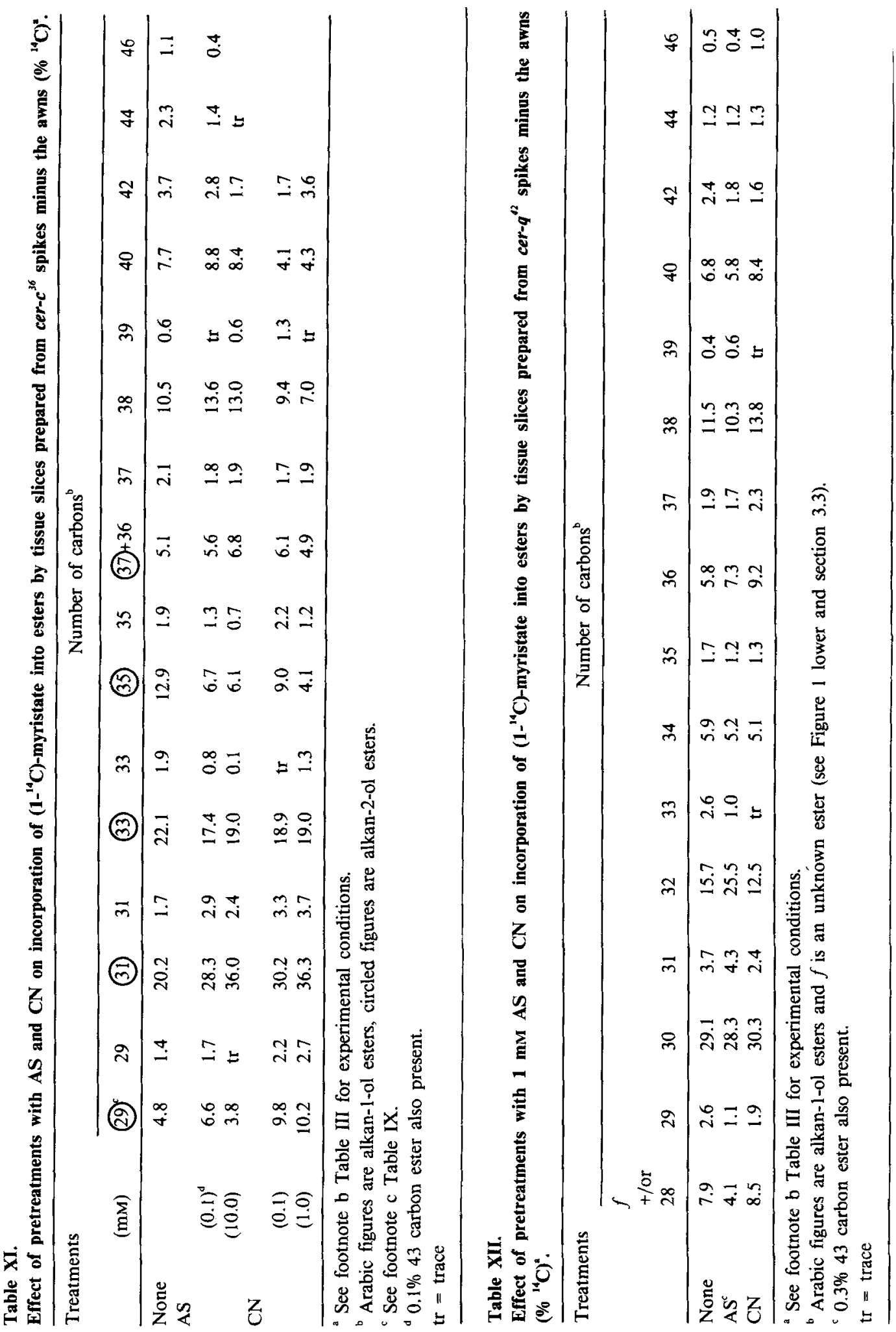


what more of a change was observed when the longer substrate $\left(\mathrm{C}_{14}\right)$ was used in that the proportion of the $\mathrm{C}_{31}-2$-ol ester was elevated (Table $\mathrm{XI}$ ) intimating a possible effect on an elongation system. The results suggest that an unlabelled pool of alkan-2-ols must have been available after AS treatment for esterification to have yielded labelled alkan-2-ol esters, and that AS does not effect the esterification reaction itself.

Pretreatments with $\mathrm{CN}$ in contrast to AS had a marked effect on the distribution of esters synthesized from $\left(1-{ }^{14} \mathrm{C}\right)-\mathrm{C}_{2}$ acid (Table $\left.\mathrm{X}\right)$ as label in the alkan-2-ol esters was noticably decreased to the advantage of the alkan-1-ol esters. Only the presumed $\mathrm{C}_{29}-2$-ol ester deviates from this generalization. Since the proportion of label in the two types of alcohol moieties was not affected (Table VI), synthesis of fatty acids to be esterified to alkan-2-ols appears more sensitive than that of those to be esterified to alkan-1ols. When $\left(1-{ }^{14} \mathrm{C}\right)-\mathrm{C}_{14}$ acid was the substrate the primary effect was a reduction in the chain lengths of the alkan-2-ol esters synthesized. The results suggest therefore, that $\mathrm{CN}$, as $\mathrm{ME}$ and probably also AS, interferes with elongation. Furthermore, certainly in the cases of AS and $\mathrm{CN}$ the effect appears to be confined to an elongation system involved in alkan-2-ol ester but not in alkan-1-ol ester synthesis. This statement is derived from the data in Table XII which clearly suggests that neither inhibitor affected the labelled ester distribution when the tissue slices were from $c e r-q^{42}$ plants. The amount of ${ }^{14} \mathrm{C}$ in the $\mathrm{C}_{30^{-1}}-\mathrm{ol}$ ester of the control cer- $q^{42}$ tissue slices (Table XII), however, is relatively greater than that in the $\mathrm{C}_{29}$-2-ol ester of the control from $c e r-c^{36}$ tissue slices (Table XI) as is also illustrated in the bottom traces of Figure 1.

\subsection{Effects of pretreatments with inhibitors on incorporation of labelled precursors into ester acids}

Table XIII presents the distributions of labelled fatty acid moieties of the esters isolated from tissue slices of $c e r-c^{36}$ after feeding various precursors for three or six hours. With one exception all are similar with respect to the relatively equal and dominating amounts of label in the $\mathrm{C}_{18}$ and $\mathrm{C}_{20}$ acids. This likeness is to some extent masked in the case of the three longer precursors since they have been both directly esterified as well as being elongated before esterification; a phenomenon which has been reported in a study on ester synthesis in jojoba seeds (25). Interestingly, direct esterification of the 12 carbon acid is much less frequent than that of the 14 and 16 carbon ones revealing a specificity of the esterification system. In the deviating distribution resulting from feeding $\mathrm{C}_{2}$ acid for six hours, the $C_{20}$ acid has twice the amount of label

Table XIII.

Distribution of ${ }^{14} \mathrm{C}$ among the acid moieties of the esters after incorporation of substrates by tissue slices prepared from $c e r-c^{36}$ spikes minus the awns (\%).

\begin{tabular}{|c|c|c|c|c|c|c|c|c|c|}
\hline \multirow[b]{2}{*}{ Substrate } & \multirow{2}{*}{$\begin{array}{l}\text { Incorporation } \\
\text { time } \\
\text { (hours) }\end{array}$} & \multicolumn{8}{|c|}{ Acid } \\
\hline & & 12 & 14 & 16 & 18 & 20 & 22 & 24 & 26 \\
\hline \multirow{2}{*}{$\left(1-{ }^{14} \mathrm{C}\right)-\mathrm{C}_{2}$} & 3 & & 2.0 & 14.2 & 33.3 & 34.3 & 10.9 & 3.1 & 1.3 \\
\hline & 6 & & & 1.7 & 26.8 & 54.2 & 12.6 & 3.8 & 1.0 \\
\hline \multirow[t]{2}{*}{$\left(1-{ }^{14} \mathrm{C}\right)-\mathrm{C}_{12}$} & 3 & 4.7 & 0.9 & 11.0 & 40.2 & 34.3 & 7.3 & 1.6 & \\
\hline & 6 & 9.0 & 2.3 & 14.7 & 35.9 & 30.6 & 6.1 & 1.4 & \\
\hline \multirow[t]{2}{*}{$\left(1-{ }^{14} \mathrm{C}\right)-\mathrm{C}_{14}$} & 3 & & 42.2 & 11.5 & 24.5 & 19.5 & 1.5 & 0.7 & \\
\hline & 6 & & 47.2 & 7.7 & 19.9 & 20.3 & 4.1 & 0.8 & \\
\hline$\left(1-{ }^{14} \mathrm{C}\right)-\mathrm{C}_{16}$ & 3 & & & 40.4 & 28.0 & 25.9 & 4.0 & 1.7 & \\
\hline$\left(2-{ }^{14} \mathrm{C}\right)-\mathrm{C}_{16}$ & 6 & & & 42.7 & 27.0 & 25.3 & 3.9 & 1.1 & \\
\hline
\end{tabular}

${ }^{a}$ Distributions are based on a minimum of $2.1 \times 10^{4} \mathrm{cpm}$, except for $\mathrm{C}_{12}-6$ hours with $0.9 \times 10^{4} \mathrm{cpm}$. 


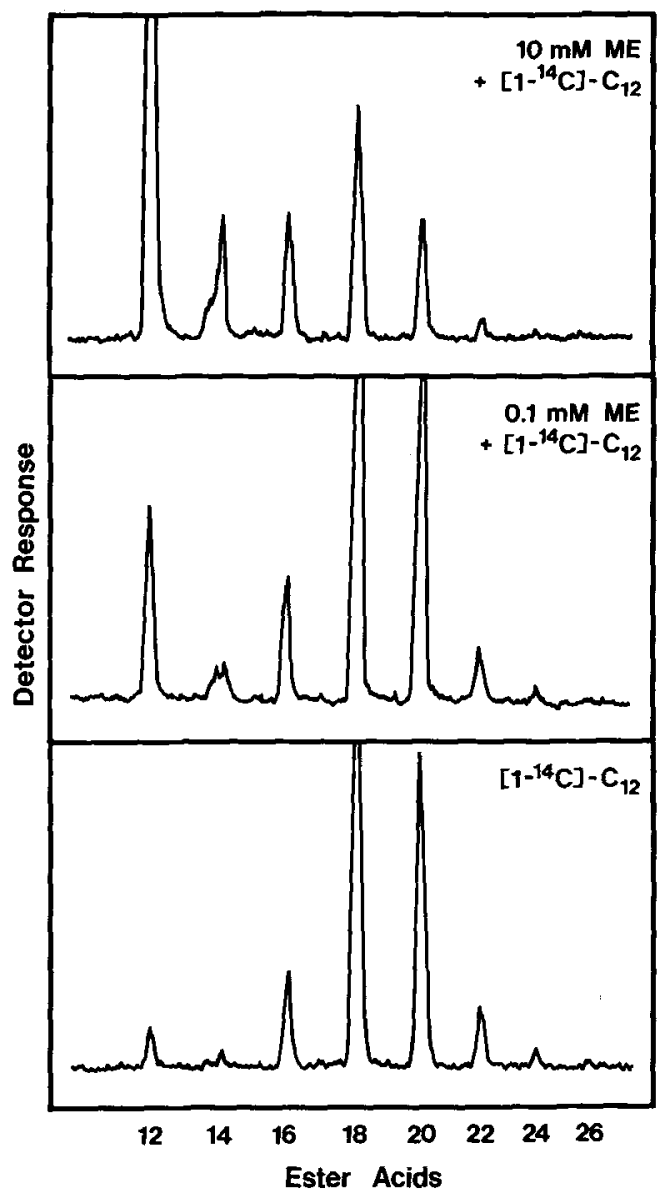

Figure 5. Effect of pretreatments with ME on the ester acid moieties synthesized from $\left(1-{ }^{14} \mathrm{C}\right)$-laurate by tissue slices prepared from $c e r-c^{36}$ spikes minus the awns as revealed by radio-GC. Isolation of the esters and separation of their transesterification plus $\mathrm{K}_{2} \mathrm{Cr}_{2} \mathrm{O}_{7}$ products are detailed in sections 2.2 and 2.3. See footnote $b$ Table III for experimental conditions. Traces represent $2.1-2.8 \times 10^{4} \mathrm{cpm}$.

that the $\mathrm{C}_{18}$ one does, and thereby most closely resembles the in vivo composition reported previously for this mutant, that is, $\mathrm{C}_{16}=6, \mathrm{C}_{18}$ $=14.8, \mathrm{C}_{20}=56.8, \mathrm{C}_{22}=18.5, \mathrm{C}_{24}=2.1$ and $C_{26}=0.3 \%$ (36). The latter distribution is indistinguishable from that of the wild type and other alleles at this locus $(35,36$, vON WETTSTEINKNOWLES unpubl.). That the radioactive distributions for the total ester acids obtained after

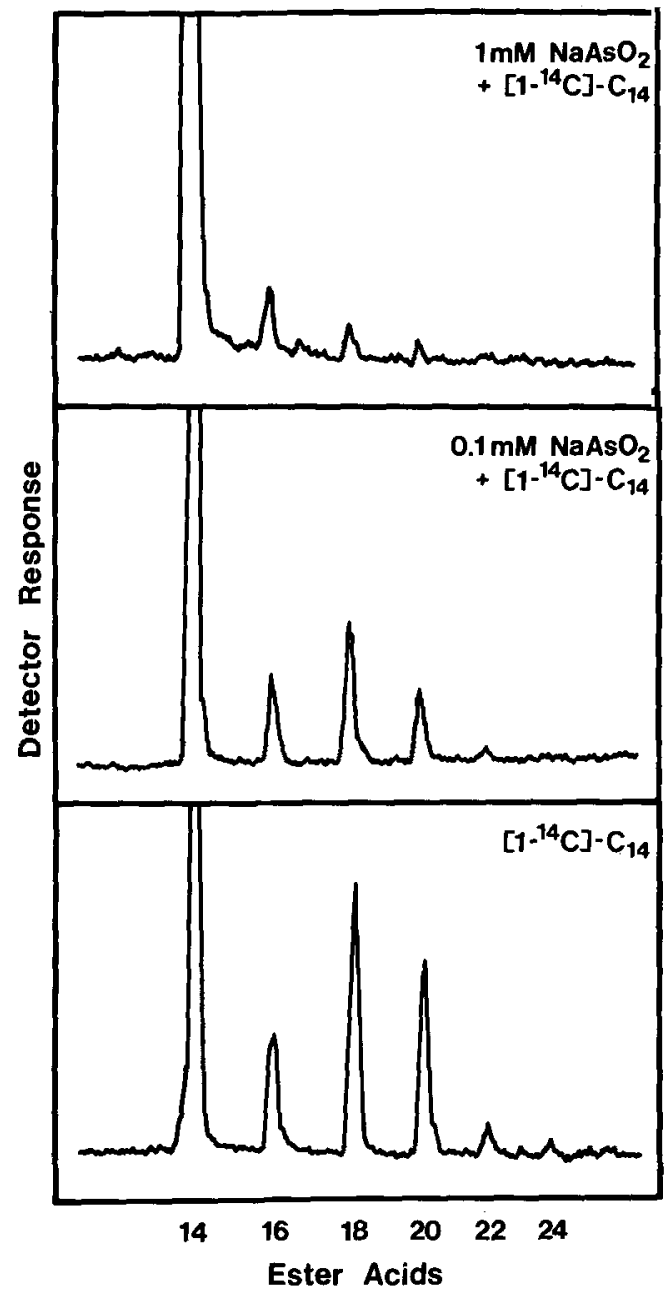

Figure 6. Effect of pretreatments with AS on the ester acid moieties synthesized from $\left(1-{ }^{14} \mathrm{C}\right)$-myristate by tissue slices prepared from $c e r-c^{36}$ spikes minus the awns as revealed by radio-GC. Isolation of the esters and separation of their transesterification plus $\mathrm{K}_{2} \mathrm{Cr}_{2} \mathrm{O}_{7}$ products are detailed in sections 2.2 and 2.3. See footnote $b$ Table III for experimental conditions. Traces represent $1.9 .2 .6 \times 10^{4} \mathrm{cpm}$.

$\mathrm{C}_{2}$ and $\mathrm{C}_{12}$ acid feeding are so similar (Table XIII) to those found for the collected, short unexpected ester acids (Table VII) intimates that the same or identical pools of acids are being esterified to the expected alkan-1-ols and alkan2-ols as to the unknown alcohols (see section 3.3). 


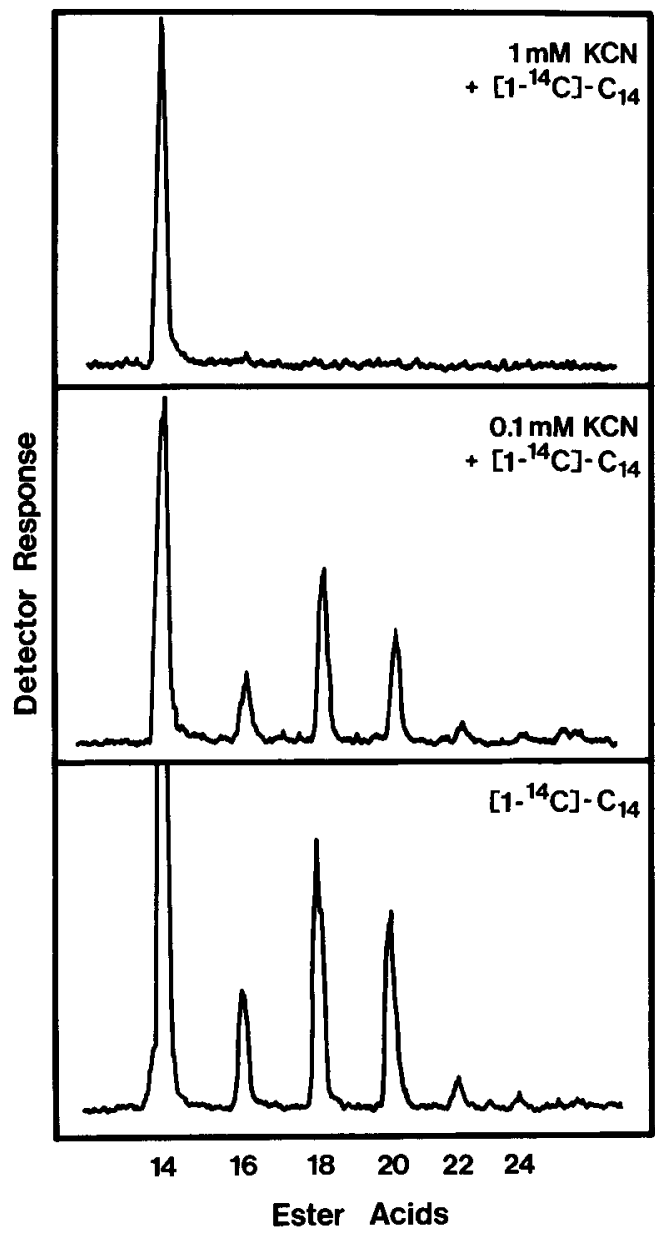

Figure 7. Effect of pretreatments with $\mathrm{CN}$ on the ester acid moieties synthesized from $\left(1-{ }^{14} \mathrm{C}\right)$-myristate by tissue slices prepared from $\mathrm{cer}-\mathrm{c}^{36}$ spikes minus the awns as revealed by radio-GC. Isolation of the esters and separation of their transesterification plus $\mathrm{K}_{2} \mathrm{Cr}_{2} \mathrm{O}_{7}$ products are detailed in sections 2.2 and 2.3. See footnote $b$ Table III for experimental conditions. Traces represent $0.8-1.8 \times 10^{4} \mathrm{cpm}$.

The most frequently invoked explanation above of the effect of inhibitors on the distributions of labelled esters synthesized subsequent to $\mathrm{ME}, \mathrm{AS}$ or $\mathrm{CN}$ exposure (section 3.4) was an inhibitory effect on elongation. This deduction was confirmed by radio-gas chromatographic scans of the ester acids. In Figures 5, 6 and 7 exposure to increasing amounts of inhi-

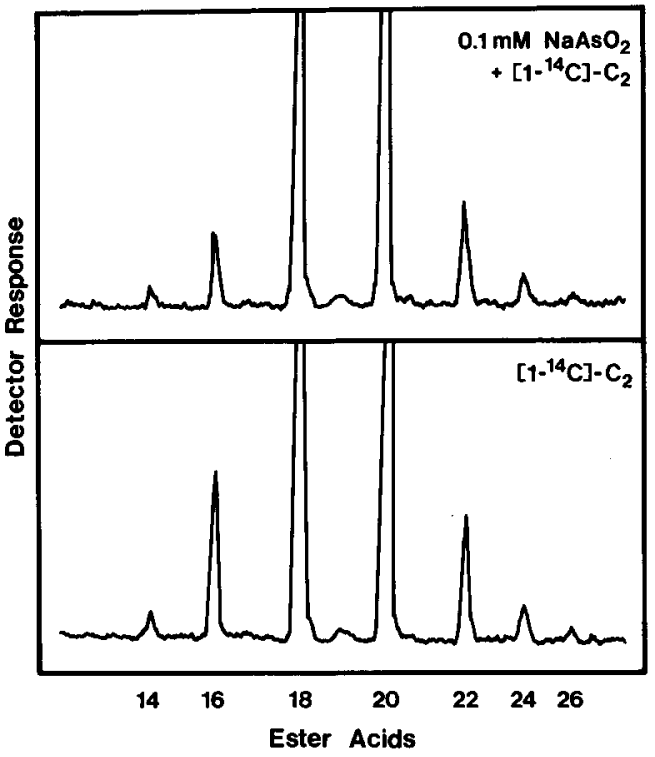

Figure 8. Effect of pretreatments with AS on the ester acid moieties synthesized from $\left(1-{ }^{14} \mathrm{C}\right)$-acetate by tissue slices prepared from $c e r-c^{36}$ spikes minus the awns as revealed by radio-GC. Isolation of the esters and separation of their transesterification plus $\mathrm{K}_{2} \mathrm{Cr}_{2} \mathrm{O}_{7}$ products are detailed in sections 2.2 and 2.3 . See footnote $b$ Table III for experimental conditions. Traces represent $2.4-3.1 \times 10^{4} \mathrm{cpm}$.

bitor preceeding feeding of 12 or 14 carbon acids is shown to result in increased direct esterification of the substrate accompanied by decreased elongation before esterification. The distributions of labelled ester acids synthesized from $\mathrm{C}_{2}$ acid after preincubation with $0.1 \mathrm{mM}$ AS (Figure 8) or CN (not shown), however, are indistinguishable from that of the control as predicted from the data in Table X. Presumably at this concentration a sufficient pool of unlabelled fatty acyl chains is present to which the labelled acetate can be added so that no effect of the pretreatments is detectable. This phenomenon has been encountered previously with AS in studies of the origin of the $\beta$-diketone carbon chain (23).

When the ester acids from $\mathrm{C}_{14}$ acid fed $c e r-q^{42}$ tissue slices were subjected to radio-GC, more label was found in the 14 carbon ester acids (56 and 66\% in two different three hours feeding 
experiments) than when $c e r-c^{36}$ tissue slices were used (Table XIII). The distribution was intermediate to those of the 0.1 and $1 \mathrm{mM} \mathrm{CN}$ treatments illustrated in Figure 7. Pretreatment of the cer- $q^{42}$ tissue slices with $1 \mathrm{mM} \mathrm{CN}$ or AS increased the amount of label in the 14 carbon ester acids to approx. $90 \%$ revealing an effect upon elongation that was not detectable in the radio-gas chromatogram of the total esters (Table XII). Reconciliation of these observations requires that as the chain length of the acid moieties of the esters decreases longer members of a pool of available alkan-1-els are being preferentially esterified in $c e r-q^{42}$ tissue slices. This does not happen in $c e r-c^{36}$ tissue slices as the available alcohol moieties are alkan-2-ols (see section 3.4) rather than alkan-1-ols.

\subsection{Effects of pretreatments with inhibitors on incorporation of labelled precursors into ester alcohols}

The observations that the inhibitors being studied could interfere with elongation of ester acid moieties suggested one should ascertain whether formation of the alcohol moieties was similarly influenced. Thus, an aliquot of the esters from the pooled $C_{12}$ acid experiment (Figure 2E) was subjected to base hydrolysis and TMS derivatives of the alcohol moieties prepared. Radio-gas chromatographic analysis gave the following distribution of ${ }^{14} \mathrm{C}: \mathrm{C}_{13}=18.6, \mathrm{C}_{15}$ $=72.6, \mathrm{C}_{14}=1, \mathrm{C}_{18}=1.2, \mathrm{C}_{20}=0.9, \mathrm{C}_{22}=1.7$, $C_{24}=1.1$ and $C_{26}=2.9 \%$. Less label was present in the even chain alkan-1-ols than expected from the results shown in Tables II and III although the amount is not so different from the mass composition ( $83 \%$ alkan-2-ols, $17 \%$ alkan-1-ols, VON WETTSTEIN-KNOWLES unpubl.). The relative proportions of carrier and endogenous alcohols might be the cause for this observation as discussed in section 2.4. By comparison an identical analysis of the ester alcohols from cer- $u^{69}$ tissue slices labelled in the same manner as those from $c e r-c^{36}$ (accumulated during the course of other studies by J.D. MIKKELSEN, 21) gave a ${ }^{14} \mathrm{C}$ distribution of $\mathrm{C}_{13}=8.5, \mathrm{C}_{15}=27.4$, $\mathrm{C}_{14}=1.7, \mathrm{C}_{16}=1.0, \mathrm{C}_{18}=2.0, \mathrm{C}_{20}=4.4, \mathrm{C}_{22}$ $=3.3, C_{24}=7.7, C_{26}=7.4, C_{28}=6.2, C_{30}=12.6$ and $C_{32}=17.6$. In this case the two types of

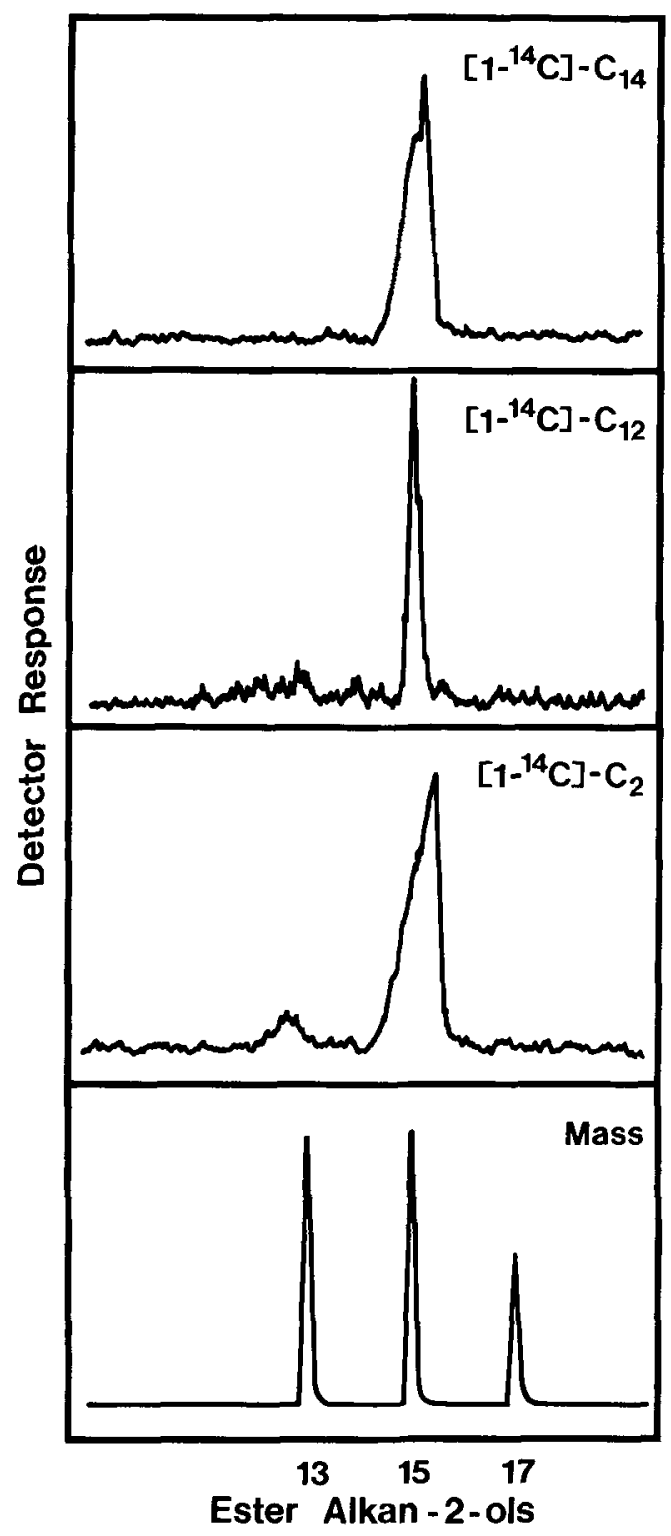

Figure 9. Effect of labelled precursors on the ester alkan-2-ol moieties synthesized by tissue slices prepared from $c e r-c^{36}$ spikes minus the awns as revealed by radio-GC of their methyl ketone derivatives. Isolation of the esters, separation of their transesterification products and preparation of methyl ketone derivatives are detailed in sections 2.2 and 2.3. See footnote $b$ Table III for experimental conditions. Approx. 6 and $4 \times 10^{3} \mathrm{cpm}$ were injected into the radio-gas chromatograph described in reference (22) to obtain the 0.1 $\mathrm{mM}$ and $10 \mathrm{mM}$ traces, respectively. By contrast the approx. $6.1 \times 10^{3} \mathrm{cpm}$ of the control sample had been injected several years previously into the radio-GC described in reference (21). 
alcohols are labelled in amountsclosely approximating their in vivo mass composition (35). Regardless of the relative efficiencies of labelling of the longer vs shorter alcohols, the \% distribution of label between the 13 and 15 carbon alkan-2-ols are remarkably similar (20.4:79.6 and 23.7:76.3, respectively).

Total ester alcohol samples were not available from the inhibitor experiments, as they had been converted to free acids and methyl ketones (Table II, footnote a) to enable analyses of the relative effects of the inhibitors on the three ester moieties to be made. In only a few instances could alkan-2-ols be recovered as their methyl ketone derivatives after TLC. Radio-GC of the latter (Figure 9) revealed that while both labelled 13 and 15 carbon alkan-2-ols were synthesized from $\mathrm{C}_{2}$ and $\mathrm{C}_{12}$ acids, only the longer was labelled when $\mathrm{C}_{14}$ acid was the precursor (32) which is in accord with other precursor experiments (22). The necessity of adding carrier alkan-2-ols before transesterification is illustrated by the minor amount of label in the $\mathrm{C}_{13}$ alkan-2-ol after $C_{12}$ acid feeding (Figure 9) compared to that expected from the radio-gas chromatographic analyses of the total alcohols presented above. On the other hand too much carrier gave the non-symmetrical peaks in the $\mathrm{C}_{2}$ and $\mathrm{C}_{14}$ acid labelled samples.

Similar analyses of ester alkan-2-ol moieties synthesized from $\mathrm{C}_{12}$ acid after ME pretreatments are shown in Figure 10. While the 24.8:75.2 ratio of label in $\mathrm{C}_{13}$ and $\mathrm{C}_{15}$ alkan-2-ols after $0.1 \mathrm{mM}$ ME treatment indicates no effect, the higher ME concentration reduced the relative amount of the $C_{15}$ alkan-2-ol to give a 34:66 ratio. Thus, ME does effect elongation of ester alkan-2-ol precursors but much less severely than that of the ester acid precursors (Figure 5).

\section{CONCLUSIONS}

Figure 11 summarizes the available information as to the sites of action of ME, AS and $\mathrm{CN}$ in the barley epicuticular wax biosynthetic pathways. All three substances were previously shown to perturb specific elongation steps in the acyl elongase pathways as indicated at the bottom of the figure (20). Present results reveal

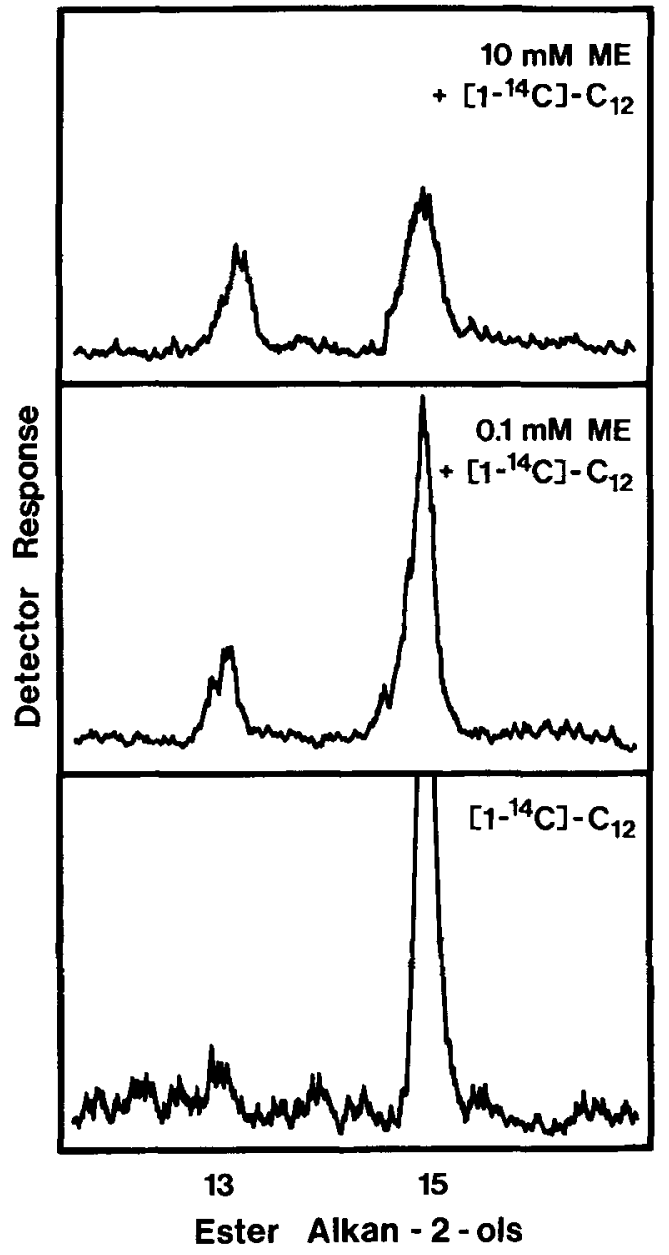

Figure 10. Effect of pretreatments with $\mathrm{ME}$ on the ester alkan-2-ol moieties synthesized from (1- $\left.{ }^{19} \mathrm{C}\right)$-laurate by tissue slices prepared from $c e r-c^{36}$ spikes minus the awns as revealed by radio-GC of their methyl ketone derivatives. Isolation of the esters, separation of their transesterification products and preparation of methyl ketone derivatives are detailed in sections 2.2 and 2.3. See footnote b Table III for experimental conditions. Control experiment is the same as that shown in Figure 9. Approx. 6.5 and $11 \times 10^{3} \mathrm{cpm}$ were injected to obtain the $C_{14}$ and $C_{2}$ traces, respectively.

that they also inhibit elongation of the shorter fatty acyl chains that serve as precursors for the ester acid moieties. Furthermore, elongation of alkan-2-ol precursors was impeded by ME (AS and $\mathrm{CN}$ were not studied), which is probably a reflection of the aforementioned effect on fatty 
P. VON WETTSTEIN-KNOWLES: Synthesis of esterified alkan-2-ols

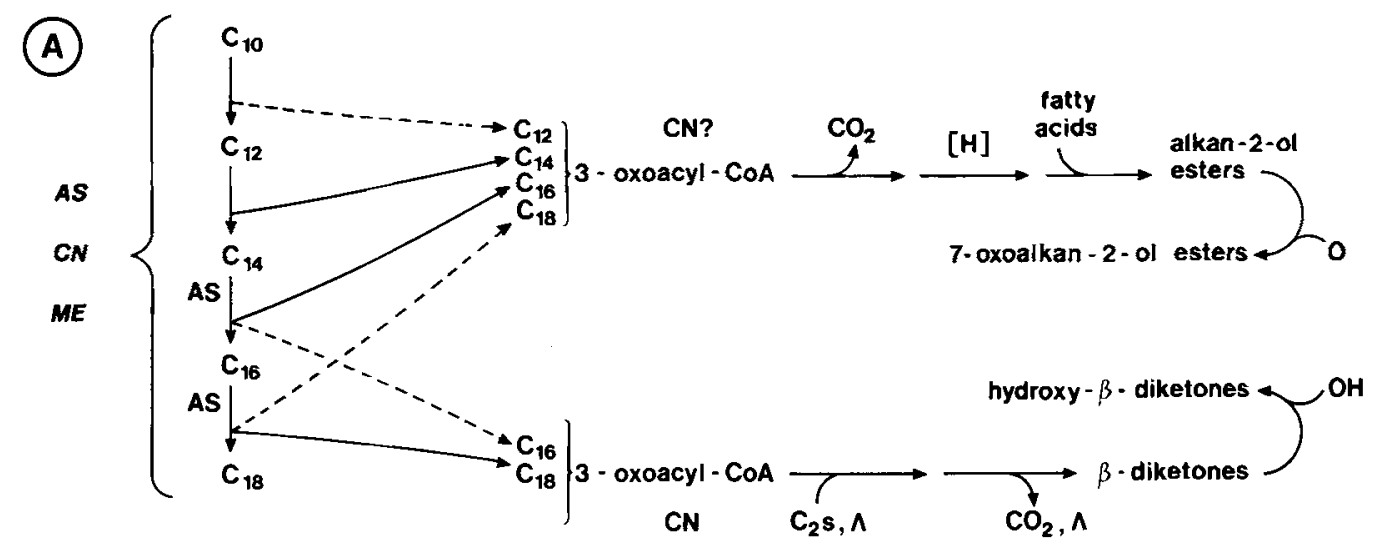

(B)

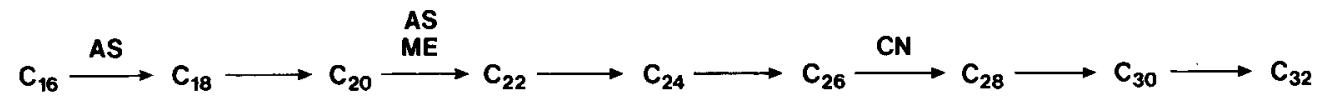

Figure 11. Sites of AS, $\mathrm{CN}$ and ME inhibition in synthesis of barley epicuticular wax lipids derived via A) the $\beta$-ketoacyl elongase and $B$ ) the acyl elongases. In the course of adding $C_{2}$-units to $C_{10}-C_{16}$ fatty acyl chains, the $\beta$-ketoacyl elongase produces 3-oxoacyl-CoAs. They can serve as precursors (22) for the alkan-2-ol and 7-oxoalkan-2-ol esters by the sequential reactions of a decarboxylase, reductase and ester synthease (22). An oxo group may be inserted (33). Alternatively, protection $(h)$ of two oxo groups, and addition of $C_{2}$-units by the $\beta$-ketoacyl elongase, followed by removal of the protection and an apparent decarboxylation gives rise to the $\beta$-diketones (23). A hydroxyl group can be inserted therein (29). Solid and dashed arrows indicate major and minor pathways, respectively. Cursive inhibitor symbols indicate a non-specifc inhibition of elongation.

acyl chain elongation. Varying sensitivities to three sulfhydryl reagents (ME, dithiothreitol and glutathione) have been reported for the elongating ability of a fas preparation from potato tuber (12).

No specific sites of ME action were identified from the present work. The decarboxylation step in alkan-2-ol synthesis was insensitive as is that in $\beta$-diketone synthesis (23). The primary effect of $\mathrm{ME}$ in barley is the $\mathrm{C}_{20}-\mathrm{C}_{22}$ block with at most a minor influence on the decarboxylation step in hydrocarbon synthesis (20). The latter, however, was designated the primary site of ME action in peas (4).

AS specifically prevented incorporation of $\left(1-{ }^{14} \mathrm{C}\right)-\mathrm{C}_{14}$ acid into $\mathrm{C}_{15}$ alkan-2-ols. This result is quite unexpected as de novo synthesis of 16 carbon chains by fas appears resistant to AS (26). I suggest, therefore, that the elongation steps which yield alkan-2-ol precursors are not carried out by fas, but by another elongation system, namely the $\beta$-ketoacyl elongase. The latter, rather than $\mathrm{C}_{16}$ elongase as originally suggested (23), also presumably functions in synthesis of the $C_{18}$ 3-oxoacyl-CoA precursor of the $\beta$-diketones. AS is not shown acting, although it may well do, at the $\mathrm{C}_{10}-\mathrm{C}_{12}$ or the $\mathrm{C}_{12}-\mathrm{C}_{14}$ steps as experimental data is lacking. Whether or not the condensing activity of the $\beta$-ketoacyl elongase complex is the site of AS action as in the $\mathrm{C}_{16}$ elongase will be resolved with the isolation of the cer-cqu gene determined polypeptide (36), one of whose functions is the designated enzyme activity $(22,24)$.

Earlier studies demonstrated that $\mathrm{CN}$ specifically inhibited $\beta$-diketone synthesis at concentrations stimulating the formation of all other wax lipid classes $(20,23)$. This result participated in assigning the major site (not shown in the Figure) of $\mathrm{CN}$ action to the branch point of the $\beta$-ketoacyl elongase pathways from those of the acyl elongases previous to 3-oxoacyl formation (20). While alkan-2-ol synthesis was somewhat more sensitive than that of the ester alkan- 
1-ols in the present analyses, it did not differ markedly from hydrocarbon sensitivity. This apparent conflict can be circumvented if $\mathrm{CN}$ does not effect 3-oxoacyl formation per se. I suggest rather that the site of $\mathrm{CN}$ sensitivity is at a place where a domain of the $\beta$-ketoacyl elongase abuts a domain of the enzymes or complexes thereof yielding either alkan-2-ols or $\beta$-diketones. Such a juxtaposition can certainly exist in $\beta$-diketone synthesis, since the condensing activity of the $\beta$-ketoacyl elongase and two later occurring enzyme activities in the pathway are all part of the same cer-cqu gene determined polypeptide (36). Therefore, 3-oxoacyl precursors leading to the two branches in the $\beta$-ketoacyl elongase derived lipid pathways have been diagrammed separately, and the site and potential site of $\mathrm{CN}$ action are shown at, not previous to the 3-oxoacyl precursors.

\section{ACKNOWLEDGEMENTS}

I am indebted to J.D. MIKKELSEN for many discussions and for carrying out the experiment in Tabel VIII; to M. PETERSEN for outstanding technical assistance; to A.S. STEINHOLTZ and N. RASMUSSEN for preparing the figures; to L. TRILlOT and H.T. NIELSEN for typing the manuscript; and to the personnel of the Phytotron in Stockholm for growing the plants.

\section{REFERENCES}

1. Allebone, J. E., R. J. Hamilton, B. A. Knights, B.S. Middeeditch \& D. M. Power: Cuticular leaf waxes. Part II. Chenopodium album L. and Lolium perenne L. Chem. Phys. Lipids 4, 37-46 (1970)

2. Avato, P., J.D. Mikkelsen \& P. von WettSteinKNOWLES: Effect of inhibitors on synthesis of fatty acyl chains present in waxes on developing maize leaves. Carlsberg Res. Commun. 45, 329-347 (1980)

3. Avato, P., J. D. Mikkelsen \& P. von Wettstein. KNOWLES: Synthesis of epicuticular primary alcohols and intracellular fatty acids by tissue slices

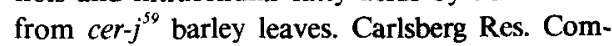
mun. 47, 377-390 (1982)

4. Buckner, J. S. \& P. E. Kolattukudy: Specific inhibition of alkane synthesis with accumulation of very long chain compounds by dithioerythritol, dithiotreitol, and mercaptoethanol in Pisum sati. vum. Arch. Biochem. Biophys. 156, 31-45 (1973)

5. Buckner, J. S., D. R. Nelson, C. L. Fatland, H. HAKK \& J. G. POMONIS: Novel surface lipids of diapausing Manduca sexta pupae. Long chain oxoalcohol esters of acetoacetic, hydroxybutyric, and acetic acids. J. Biol. Chem. 259, 8461-8470 (1984)

6. Dormling, I., Ȧ. Gustafsson, H. R. Jung \& D. vON WETTSTEIN: Phytotron cultivation of Svalö's Bonus barley and its mutant Svalö's Mari. Hereditas (Lund) 56, 221-237 (1966)

7. Dormling, I., Ȧ. Gustafsson \& D. von WettSTEIN: Phytotron cultivation of Bonus barley: The control of maturation and grain quality. Hereditas (Lund) 63, $415-428$ (1969)

8. FIESER, L. F. \& M. FiESER: Reagents for Organic Synthesis. John Wiley and Sons Inc. N. Y., pp. 453, 873-874 (1967)

9. Hamilton, R. J., M. Y. Raie \& I. Weatherston: Surface lipids of Ligia oceanica; Part II: The ester fractions. J. Am. Oil Chem. Soc. 53, 748-751 (1976)

10. HARwood, J. L. \& P. K. STUMPF: Fat metabolism in higher plants. XLIII. Control of fatty acid synthesis in germinating seeds. Arch. Biochem. Biophys. 142, 281-291 (1971)

11. HARwoOd, J. L. \& P. K. STUMPF: Fat metabolism in higher plants. LI. Palmitic and stearic synthesis by an avocado supernatant system. Arch. Biochem. Biophys. 148, 282-290 (1972)

12. Huang, K. P. \& P. K. StumpF: Fat metabolism in higher plants. XLIV. Fatty acid synthesis by a soluble fatty acid synthetase from Solanum tuberosum. Arch. Biochem. Biophys. 143, 412-427 (1971)

13. HøJ, P. B. \& J. D. Mikkelsen: Partial separation of individual enzyme activities of an ACP-dependent fatty acid synthetase from barley chloroplasts. Carlsberg Res. Commun. 47, $119-141$ (1982)

14. Jaworski, J. G., E. E. Goldschmidt \& P. K. STUMPF: Fat metabolism in higher plants. Properties of the palmityl acyl carrier protein: Stearyl acyl carrier protein elongation system in maturing safflower seed extracts. Arch. Biochem. Biophys. 163, 769-776 (1974)

15. Jewett, D. M., F. Matsumura \& H. C. Coppel: Sex pheromone specificity in the pine sawflies: interchange of acid moieties in an ester. Science 192, $51-53$ (1976)

16. Kannangara, C. G. \& P. K. Stumpf: Fat metabolism in higher plants. XLVII. The effect of nitrite and other anions on the formation of unsaturated fatty acids by isolated chloroplasts. Plant Physiol. 49, 497-501 (1972)

17. Khan, A. A. \& P. E. Kolattukudy: Control of 
synthesis and distribution of acyl moieties in etiolated Euglena gracilis. Biochemistry 12, 1939. 1948 (1973)

18. Kolattukudy, P. E.: Biosynthesis of wax in Brassica oleracea. Biochemistry 4, 1844-1855 (1965)

19. LundQVist, U. \& P. von WeTtSTEIN-KNOWLES: Phenotypic diversity of barley spike waxes resulting from mutations at locus cer- $n$. Carlsberg Res. Commun. 48, 321-344 (1983)

20. Mikkelsen, J. D.: The effects of inhibitors on the biosynthesis of the long chain lipids with even carbon numbers in barley spike epicuticular wax. Carlsberg Res. Commun. 43, 15-35 (1978)

21. Mikkelsen, J. D.: Structure and biosynthesis of $\beta$-diketones in barley spike epicuticular wax. Carlsberg Res. Commun. 44, 133-147 (1979)

22. Mikkelsen, J. D.: Biosynthesis of esterified alkan-2-ols and $\beta$-diketones in barley spike epicuticular wax: synthesis of radioactive intermediates. Carlsberg Res. Commun. 49, 391-416 (1984)

23. Mikkelsen, J. D. \& P. von Wettstein-KNOWLES: Biosynthesis of $\beta$-diketones and hydrocarbons in barley spike epicuticular wax. Arch. Biochem. Biophys. 188, 172-181 (1978)

24. Mikkelsen, J. D. \& P. von WetTSTEIN-KNOWLES: Biosynthesis of esterified alkan-2-ols in barley spike epicuticular wax. In: Structure, function and metabolism of plant lipids. P. -A. Siegenthaler \& W. Eichenberger, eds., Elsevier Science Publ. B. V., Amsterdam, pp. $517-520$ (1984)

25. Ohlrogge, J. B., M. R. Pollard \& P. K. StumpF: Studies on biosynthesis of waxes by developing jojoba seed tissue. Lipids 13, 203-210 (1978)

26. Shimakata, T. \& P. K StumpF: Isolation and function of spinach leaf $\beta$-ketoacyl-[acyl-carrierprotein] synthases. Proc. Natl. Acad. Sci. USA 79, 5808-5812 (1982)

27. Wettstein, D. von: The Phytotron in Stockholm. Studia Forest. Suecica 44, 1-23 (1967)
28. Wettstein-Knowles, P. von: The molecular phenotypes of the eceriferum mutants. In: Proc. 2nd. Int. Barley Genet. Symp., (1969). R. A. Nilan, ed., Washington State Univ. Press, Pullmann, Wash., USA. pp. 146-193 (1972)

29. WeTtSTEIN-KNOWLES, P. vON: Genetic control of $\beta$-diketone and hydroxy- $\beta$-diketone synthesis in epicuticular waxes of barley. Planta (Berl. ) 106, 113-130 (1972)

30. WettStein-KNOWLES, P. von: Gene mutation in barley inhibiting the production and use of $\mathrm{C}_{26}$ chains in epicuticular wax formation. FEBS Lett. 42, 187-191 (1974)

31. WETTSTEIN-KNOWLES, P. voN: Biosynthetic relationship between $\beta$-diketones and esterified alkan2-ols deduced from epicuticular wax of barley mutants. Molec. gen. Genet. 144, $43-48$ (1976)

32. Wettstein-KNowles, P. von: Biosynthesis of epicuticular lipids as analyzed with the aid of gene mutations in barley. In: Biochemistry and metabolism of plant lipids. J. F. G. M. Wintermans \& P. J. C. Kuiper, eds., Elsevier/North Holland Biomedical Press. Amsterdam, pp. $69-78$ (1982)

33. Wettstein-Knowles, P. von \& J. Ø. Madsen: 7-Oxopentadecan-2-ol esters - a new epicuticular wax lipid class. Carlsberg Res. Commun. 49, 57-67 (1984)

34. Wettstein-KNowles, P. von, J. D. MikKelsen \& J. Ø. MADSEN: Nonan-2-ol esters in sorghum leaf epicuticular wax and their collection by preparative gas chromatography. Carlsberg Res. Commun. 49, 611-618 (1984)

35. Wettstein-KnOwles, P. von \& A. G. Netting: Esterified alkan-1-ols and alkan-2-ols in barley epicuticular wax. Lipids 11, 478-484 (1976)

36. WeTtSTEIN-KNOWLES, P. von \& B. SøgaARd: The cer-cqu region in barley: gene cluster or multifunctional gene. Carlsberg Res. Commun. 45, 125-141 (1980)

Accepted by S. O. ANDERSEN 